Sādhanā Vol. 38, Part 1, February 2013, pp. 37-68. (C) Indian Academy of Sciences

\title{
Global stability-based design optimization of truss structures using multiple objectives
}

\author{
TUGRUL TALASLIOGLU
}

Department of Civil Engineering, Korkut Ata University, Osmaniye, 8000, Turkey

e-mail: talaslioglu@cu.edu.tr; ttalaslioglu@osmaniye.edu.tr

MS received 26 February 2010; revised 13 April 2011; accepted 13 December 2011

\begin{abstract}
This paper discusses the effect of global stability on the optimal size and shape of truss structures taking into account of a nonlinear critical load, truss weight and serviceability at the same time. The nonlinear critical load is computed by arc-length method. In order to increase the accuracy of the estimation of critical load (ignoring material nonlinearity), an eigenvalue analysis is implemented into the arc-length method. Furthermore, a pure pareto-ranking based multi-objective optimization model is employed for the design optimization of the truss structure with multiple objectives. The computational performance of the optimization model is increased by implementing an island model into its evolutionary search mechanism. The proposed design optimization approach is applied for both size and shape optimization of real world trusses including 101, 224 and 444 bars and successful in generating feasible designations in a large and complex design space. It is observed that the computational performance of pareto-ranking based island model is better than the pure pareto-ranking based model. Therefore, pareto-ranking based island model is recommended to optimize the design of truss structure possessing geometric nonlinearity.
\end{abstract}

Keywords. Nonlinear critical load; multi-objective optimization; island models; genetic algorithm; arc-length method.

\section{Introduction}

The stability strength of a truss structure is generally determined according to the magnitude of its linear buckling load computed by a local stability design method. Khot et al (1976) optimized the design of truss structures considering its linear buckling load. For this purpose, they utilized an optimality criteria approach in their design applications. In this regard, new optimization applications making use of the linear buckling load were also developed for structural design problems (Lin \& Liu 1989). However, it was shown that a local stability analysis overestimates 
the buckling load (Levy et al 2004). Therefore, the concept of global stability based on the computation of the nonlinear buckling load, also defined as nonlinear critical load or just critical load, was introduced into the stability-based design optimization (Levy et al 2004).

Plaut et al (1984) optimized the design of a small-scale truss taking into account of a critical load computed by use of a nonlinear buckling analysis. Khot \& Kamat (1985) utilized a potential energy concept for their stability-based design optimization procedure. Kamat et al (1984) used an optimality criteria approach for optimal design of truss structures by imposing a uniform strain energy density to all truss members to obtain a maximum critical load.

Levy \& Perng (1988) developed a two-phase optimization algorithm: a critical load was estimated for a specified external load; the truss structure was re-designed using an optimality criteria approach.

Levy (1994a and 1994b) showed that the values of member cross-sectional areas converged to a unique value at the end of optimization where geometric nonlinearity is taken into consideration.

Sedaghati \& Tabarrok (2000) proposed an optimality criteria approach for truss structures which exhibit snap-through and snap-back behaviour. Their optimization approach was based on imposing a uniform strain energy density to all truss members.

Another challenging optimization approach was based on using the design sensitivity information, which is obtained from the nonlinear structural analysis, for optimal design of truss structures. Cardoso \& Arora (1988) minimized the weight of truss structures utilizing its design sensitivity information. Choi \& Santos (1987) and Santos \& Choi (1988) obtained the design sensitivity information using the virtual work principle. Ohsaki (2001) proposed a similar approach based on the computation of sensitivity coefficients considering the critical loads of truss structures. Ohsaki \& Ikeda (2006) attempted to compute the sensitivity coefficients considering some critical loads, which were indicated by bifurcated or branched points located in a load-displacement curve and defined as bifurcation point, degenerate critical point and hilltop branching point. Furthermore, they also showed that computation of sensitivity coefficients failed when iterative progression was terminated due to computational problem related to the singularity of determinants or when an inappropriate objective function was used to evaluate the sensitivity coefficients (Ohsaki 2005). In order to deal with this matter, certain joint deflections were constrained to move in specified directions at a predefined upper limit.

In this study, the design of truss structures is optimized considering the critical load which is computed by arc-length method based on iteratively adjusting the system rigidity matrix for tracing a load-displacement path. The arc-length method is also improved by including an eigenvalue analysis in its iterative algorithm in order to accurately estimate the critical load. Because of the negative effect of large joint deflections on the serviceability of truss structures, a new objective function related to joint displacements is included into optimization procedure. Although the weight of truss structure is an important factor for economical reasons, a higher critical load indicates larger stability strength for that truss structure. Therefore, a total of three objective functions are employed both to minimize the joint displacement and entire weight and to maximize the critical load of the truss structure. A pure pareto-ranking based multi-objective optimization model is employed in the optimization procedure. In order to increase the computational capacity of this optimization model, an island model, developed originally for the parallelization of evolutionary algorithms, is implemented into its search mechanism.

This paper is organized as follows. First, the fundamentals of arc-length method are presented. Next, the verification of arc-length method is demonstrated with two examples. Then, the pareto ranking-based multi-objective model and the island model are briefly described along with an introduction to the optimum design procedure. A search methodology is introduced for the 
evaluation of the two multi-objective optimization models and execution of arc-length method. The discussion of results and the conclusions are also provided.

\section{Arc-length method}

The ultimate-load carrying capacity of a truss structure is determined by estimating the critical loads. But, the estimation of critical loads is difficult when a truss structure exhibits snap-through or snap-back behaviour. A discontinuity on the load-displacement path arises when the system rigidity matrix becomes indefinite; this prevents a further iterative progression in the estimation of critical loads. Therefore, the efficiency of any nonlinear solution method is measured by its capability of estimating all critical points. Arc-length method is proven to be efficient in the estimation of both the bifurcation and branching points (Kouhia \& Mikkola 1999). Thus, arc-length method is improved by implementing new strategies in its computational procedure. (Summary of recent improvements for the arc-length method can be seen in references (Kouhia \& Mikkola 1999; Memon \& Su 2004; Ritto-Correa \& Camotim 2008).

One such effective improvement is based on utilizing a constraint equation for the determination of incremental nodal displacements; hence a successful tracing is provided for the load-displacement path (Crisfield 1997). However, the constraint equation is represented by a quadratic form; when an inappropriate root is used for the constraint equation, the computational procedure fails. In order to overcome this difficulty, Krenk (1995) developed an alternative technique, called orthogonal residual method. The orthogonal residual method is based on adjusting a load increment for iterative procedures in a way of checking the orthogonality of residual force to current displacement increment (see figure 1). In this study, Krenk's arc-length method is

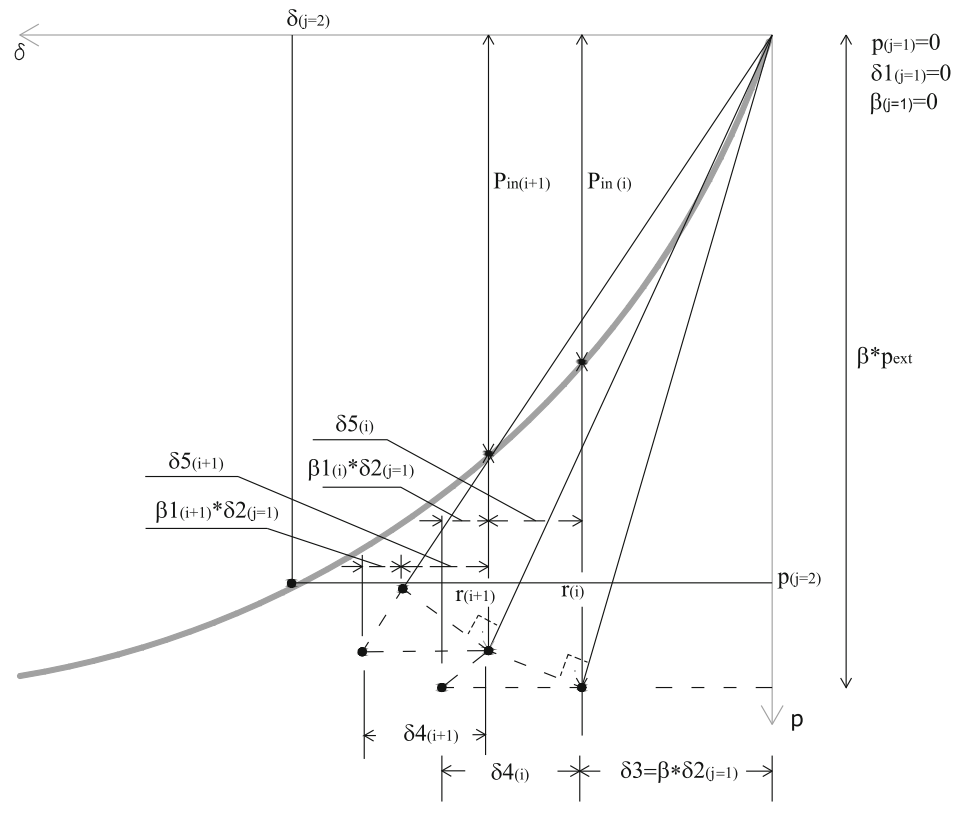

Figure 1. Iterative and incremental processes performing on load-deflection path. 
utilized to estimate the critical load (see figure 2). The formulation of element stiffness matrix for a truss bar is presented in Magnusson (2006).

Some determinant-related criteria are of importance for the computation of critical loads by arc-length method. These are

(i) Determinant of tangent stiffness matrix, $\operatorname{det}[\mathrm{K}]$.

(ii) Minimum pivot of tangent stiffness matrix, min_piv[K].

(iii) Minimum eigenvalue of tangent stiffness matrix, min_eig[K].

Although there are different possibilities of how the critical points are computed by the determinant-related criteria, the choice of $\operatorname{det}[\mathrm{K}]$ may be inappropriate either due to the possibility of missing some points that represent the critical loads or due to the numerical problems associated with the computer program (Rezaiee-Rojand \& Vejdari-Nogreiyan 2006). Therefore,

Initialization of some parameters for incremental and iterative stage

$$
\begin{aligned}
& p=[0] \\
& \delta 1=[0] \\
& \beta=1
\end{aligned}
$$

Stage of increment

$$
\text { for } \mathrm{j}=1 \text { : inc_max }
$$

1i. Compute $[K]$ using $\delta 1$

1ii. $\delta 2=[K]^{-1} * p_{\text {ext }}$

1iii. Normalize $\delta 2_{j}$ for first incremental stage and calculate $\beta$ : $\beta=\left(\right.$ normalize $\left(\delta 2_{j=1}\right) /($ normalize $(\delta 2)$

liv. Calculate $\delta 3$ for beginning of iterative procedure: $\delta 3=\beta * \delta 2$

Iterative Stage

$$
\text { for } \mathrm{i}=1 \text { : it_max }
$$

2i. Compute $p_{\text {int }}$ using $\delta 1+\delta 3$

2ii. $r=\beta^{*} p_{\text {ext }}+p_{\text {int }}-p$

2iii. Update $[K]$ using $r$

2iv. $\delta 4=[K]^{-1} * r$

$2 v . \beta 1=-(\delta 4 * \delta 3 / \delta 3 * \delta 2)$

$2 v i . \delta 5=\delta 4+\beta 1 * \delta 2$

2vii. $\delta 3=\delta 3+\delta 5$

2viii. $\beta=\beta+\beta 1$

$$
\begin{aligned}
& \text { if normalize } p_{\text {in }} \leq \varepsilon * p_{\text {ext }} \\
& \text { STOP } \\
& \text { else } \\
& \delta 2=\delta 2 / 2, \delta 3=\delta 2, p_{\text {ext }}=p_{\text {ext }} / 2 \\
& \text { end } \\
& \text { end }
\end{aligned}
$$

1v. $\delta 1=\delta 1+\delta 3$

1vi. $p=p+\beta^{*} p_{\text {ext }}$ end

Figure 2. A pseudo code for proposed arc-length method. 


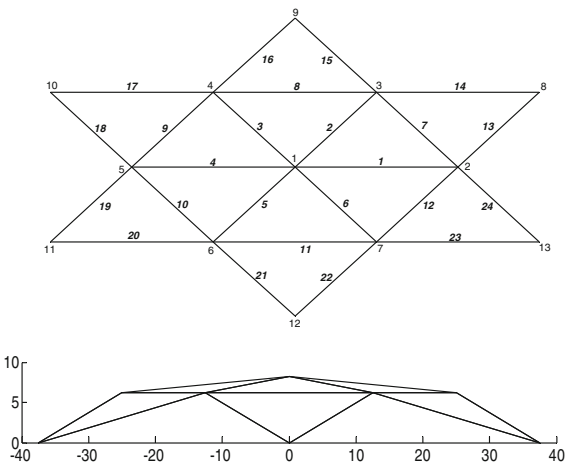

(a)

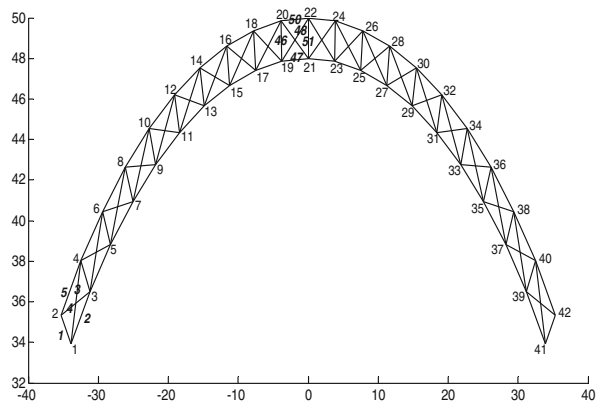

(b)

Figure 3. Mesh and geometry attributes of 24 (a) and 101 bar truss structures (b).

the best choice used as a determinant-related criterion seems to be min_eig[K]. For this purpose, an interpolation process is utilized to determine zero eigenvalues. Eigenvalues of the tangent stiffness matrix are monitored until a sign change in an eigenvalue is noticed. Then, the displacement values are interpolated between the two values corresponding to these oppositely-signed eigenvalues in order to find a displacement corresponding to the zero eigenvalue. It must be noted that the point corresponding to a zero eigenvalue may not be located on the fundamental equilibrium path.

\subsection{Demonstration of arc-length method by verification examples}

In order to demonstrate the arc-length procedure with eigenvalue analysis, two truss structures with 24 and 101 bars are analysed. The 24 bar truss structure, whose elasticity modulus and cross-sectional areas are taken as $10796 \mathrm{psi}$ and $1 \mathrm{in}^{2}$ respectively, is a star-shaped dome with a vertical load applied at its crown (figure 3a) (Wrigger et al 1988). The second verification example is a planar arch with 101 bars, which is also vertically loaded at its crown (Crisfield

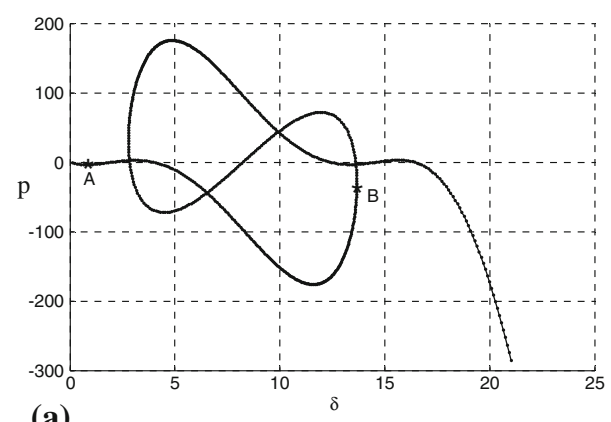

(a)

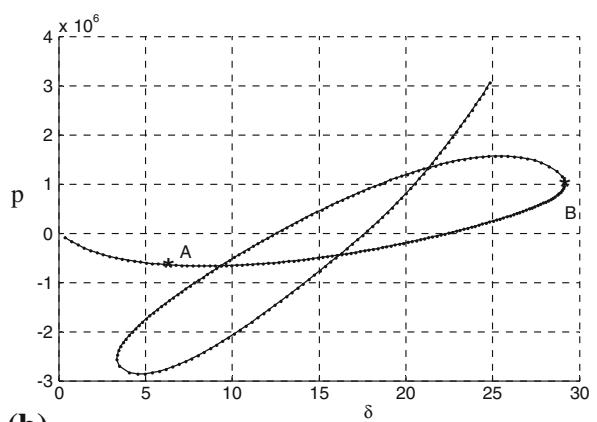

(b)

Figure 4. Post buckling plot of nonlinear responses for 24 (a) and 101 bar truss structures (b). 
Table 1. Output from execution of proposed arc-length method for 24 and 101 bar truss structures.

24 bar truss structure

The outcome from a complete run of arc-length procedure

Load corresponding to point B (kips)

Disp. corresponding to point B (in.)

Elapsed time for (in second)

Total number of increment

The outcome from computatio

Critical load corresponding to point A (kips)

Critical disp. corresponding to point A (in.)

Elapsed time (in second)

Total number of increment
30.989

13.657

10.30

87
3.332

0.7756

1.98

101 bar truss structure

1006478.352

29.139

20.12

154

620384.207

5.5739

2.24

19

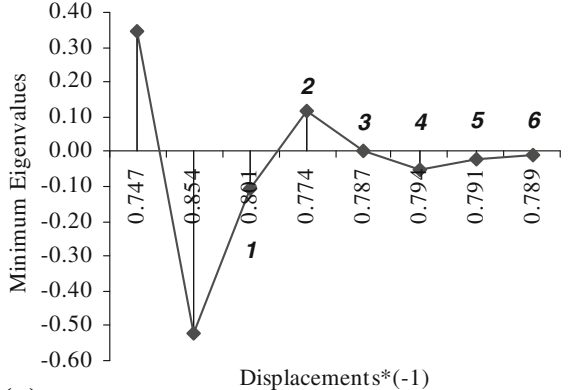

(a)

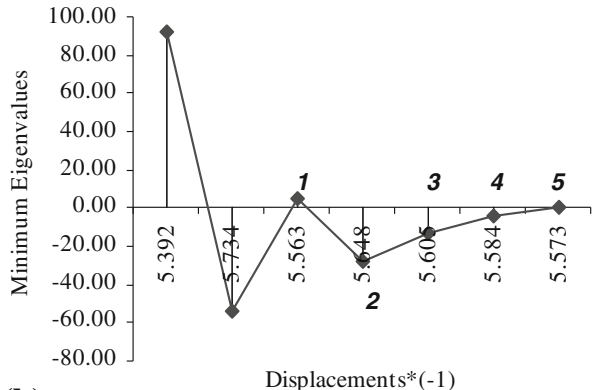

(b)

Figure 5. Variation on both minimum eigenvalues and displacements including corresponding iteration number for 24 (a) and 101 bar truss structures (b).
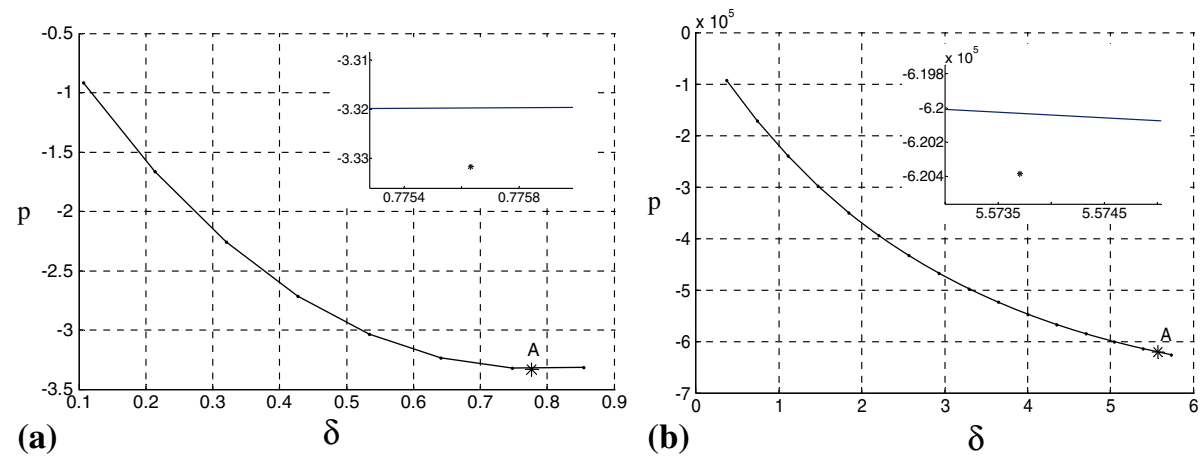

Figure 6. Locations of critical load and corresponding displacement for 24 (a) and 101 bar truss structures (b). 
1997; Gien 2007). Its members have an elasticity modulus of $5 \times 10^{7}$ psi and a cross-sectional area of $1 \mathrm{in}^{2}$ (figure $3 \mathrm{~b}$ ).

The computational procedure of the proposed arc-length method is executed allowing a maximum error of 0.001 . According to the results obtained, a load-displacement curve exhibiting snap-through and snap-back behaviour is simultaneously plotted for both truss structures (figures $4 \mathrm{a}$ and $\mathrm{b}$ ). In this post-buckling graph, the values of load and displacement corresponding to point $\mathrm{B}$ are summarized together with the computation time in table 1 . It is observed that the results obtained agree with those obtained with other approaches in Crisfield (1997); Gien (2007).

In the second step, two sequential points with oppositely-signed eigenvalues are determined. Then, an interpolation process between these two points is carried out until a zero eigenvalue is obtained. The interpolation process is illustrated for both examples in figures $5 \mathrm{a}$ and b. Figures $6 \mathrm{a}$ and $b$ display the exact values of critical loads and related displacements (point A on the graphs) corresponding to zero eigenvalue. The corresponding computation times and total increment numbers are shown in table 1.

\section{The solution of multiple objectives by island models}

Multi-objective optimization models (MOMs) vary with respect to two key issues: sampling of feasible solutions from a large and complex search space and assessing them according to convergence degrees of their optimal designations. A MOM is performed using a set of solutions (called pareto optimal set) simultaneously. In this regard, at each run of evolutionary optimization algorithm, the objective is to obtain a solution, named pareto solution, satisfying conditions of constraints lying in the feasible region. In this regard, a pareto front is represented by the pareto solutions, each of which is not dominated by the other ones and represented by a curve, called true pareto front. Points located on the true pareto front curve are not improved further. The quality of current pareto front obtained in the end of a whole genetic search is assessed according to its closeness to the true pareto front.

Evolutionary algorithms have a flexible search mechanism. In particular, they have the ability to hybridize with a pareto-ranking based MOM (PbMOM) through both letting the pareto optimal set to be handled easily and allowing the combination of multiple objectives into a single objective function (Veldhuizen \& Lamont 1998). The most popular evolutionary algorithm is the genetic algorithm. The genetic algorithm is governed by genetic operators which mimics selection and recombination within populations in nature. The genetic algorithm has been improved by new model implementations. One such model used in combination with the genetic algorithm is the island model that is developed for parallelization of genetic algorithms (Cantu-Paz 1999). It is managed by multiple populations called islands and categorized under coarse-grained models of parallel genetic algorithm. Coarse-grained models are managed by relatively few islands, each of which have a large number of individuals. The main strength of island models is their ability of handling multiple populations with different genetic parameters at the same time.

The islands are capable of exchanging their individuals through a transforming process called migration (Eby et al 1999). Migration operator is governed by a predetermined communication topology that prescribes which islands can interchange individuals. Migrating individuals (emigrants or immigrants) are determined depending on their fitness quality. The other essential parameters of migration operator are the number of emigrants or immigrants (migration rate) and the number of executions of the migration process (migration interval). 
In order to increase the computational performance of island models, some attempts, based on adjusting parameter values of genetic operators, have been made Eby et al (1999) and proposed an island model with a fixed migration frequency. Malott et al (1996) used a coarse island model with slowly varying migration rates. One variation involves a competition which is based on reshuffling of islands with regard to their individuals' fitness values (Schlierkamp-Voosen and Mühlenbein 1996). The essential parameters of competition operator are the competition rate and interval.

\section{Design problem}

In order to solve the optimization problem for the geometrically nonlinear truss structures, three objective functions are proposed. The maximization of limit load $L(X)$, the minimization of truss weight $W(X)$ and joint deflection $\delta(X)$. Design variables $X$ contain cross-sectional areas $A$, joint coordinates $x, y$ and $z$ of truss structure. It is noted that additional design variables, for example radius of arch, distance between joints, etc. are used to define the shape of truss structures. The problem can be formulated mathematically as

$$
\left.\begin{array}{l}
X \in A_{i}, x_{j}, y_{j}, z_{j} \quad(i=1, \ldots, n d a),(j=1, \ldots, n n) \\
\max L(X)=\max (\text { critical load capacity corresponding to state of } \operatorname{det}[K]=0) \\
\min \delta(X)=\min \left(\delta_{m}\right) \quad(m=1, \ldots, n n) \\
\min W(X)=\min \left(\sum_{m=1}^{n e} A_{m} * L_{m} * \rho\right) \quad(m=1, \ldots, n t m),
\end{array}\right\}
$$

where $\rho, n d a, n n$ and $n t m$ represent material density, number of different cross-sectional areas, nodes and truss members, respectively.

\section{Optimum design procedure}

Islands models have the ability of investigating the different regions of complex search space, thereby using different parameter values for the same genetic operators. They need to be modified for multi-objective optimization procedure. In this study, all pareto optimal solutions computed through different objective functions are combined into a single pareto optimal set and then ranked. These ranked values are used to both arrange the order of islands and redistribute the individuals to different islands. The proposed algorithm, named pareto-ranking based multi-objective island model (PbMIM), is detailed in figure 7.

(i) Initialize the islands by assigning randomly-generated numbers to its individuals which of chromosomes are coded using design variables of continuous type.

(ii) Specify a combination set, which contains the cross-sectional areas and joint coordinates.

(iii) Execute the proposed arc-length method and compute objective functions.

(iv) Execute the ranking process for values of combined fitness functions. If required, apply the ranking share procedure based on re-scaling of fitness values according to their rank (Goldberg \& Richardson 1987).

(v) Select the individuals with higher computational performance according their fitness values and store in the 'pool of best individuals'.

(vi) Re-order the islands in a descending order with respect to fitness values (see figure 7). 


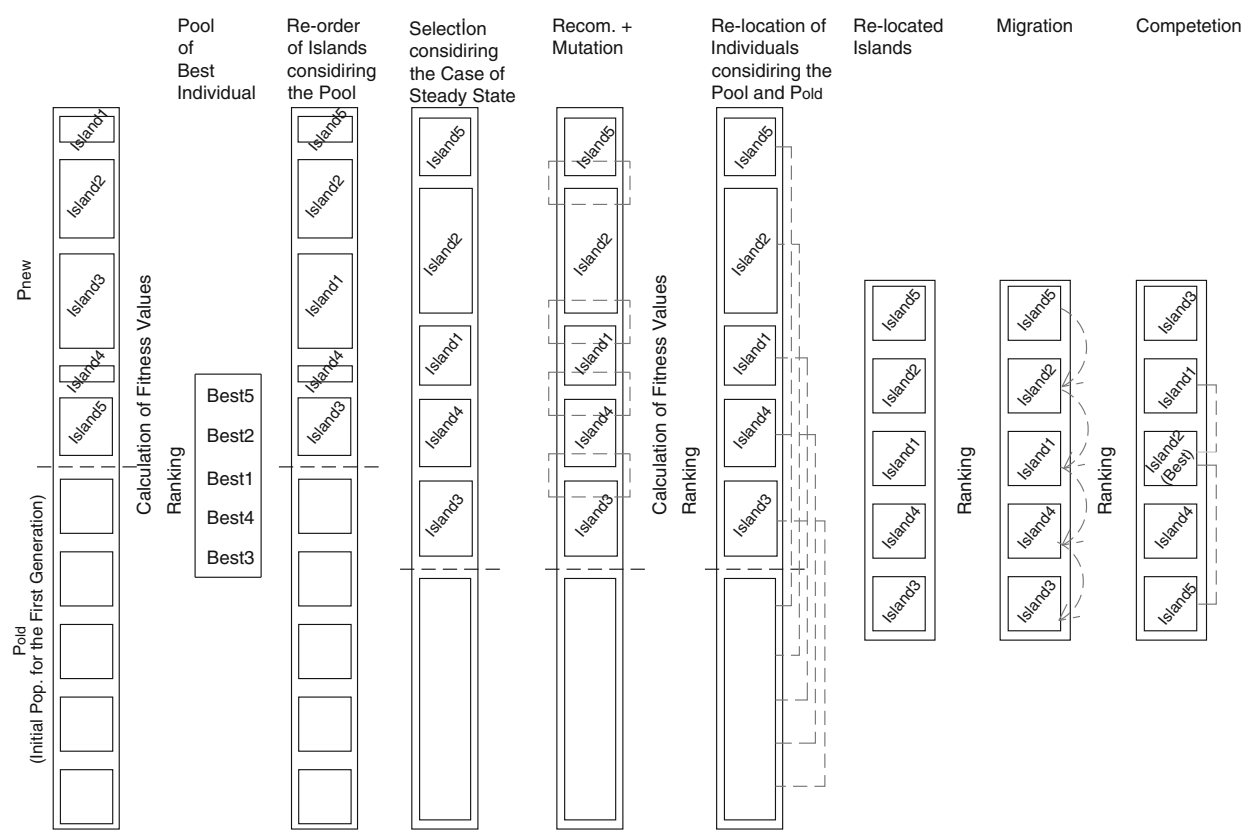

Figure 7. Depiction of the proposed island model for the design of multi-objective optimization procedure.

(vii) Mate a randomly-chosen individuals located in different islands and apply crossover operator at pre-determined rates; choose randomly an individual and apply mutation operator at predetermined rate (see parameters values of genetic operators in table 2) (Polheim 1998).

(viii) Select the individuals using a selection operator (see table 2) and re-create both the current island considering these individuals and the pool of best individuals.

(ix) Migrate the individuals to the related islands using a ring-shaped migration topology (table 2) and a migration policy which is determined by 'the best fitness value' obtained from the pool of best individuals.

(x) Assign the individuals, determined by the competition operator, to the related islands depending on the competition rate.

(xi) Replace the initial island with the current island and repeat steps 2-10 until the predetermined number of generations is completed.

The computational procedure of PbMOM contains only the steps $1-4$. Following the step 4, the individuals with higher computational performance are selected according to their fitness values and used to create the next population. These steps are repeated until a predetermined number of generations is completed. Therefore, the search mechanism of PbMOM is considerably simpler than PbMIM's.

\section{Search methodology}

According to the traditional search methodology, the computational performances of MOMs are assessed considering closeness of their current pareto fronts obtained to a true pareto front known beforehand (Talaslioglu 2010). This is accomplished by utilizing the quality measuring 


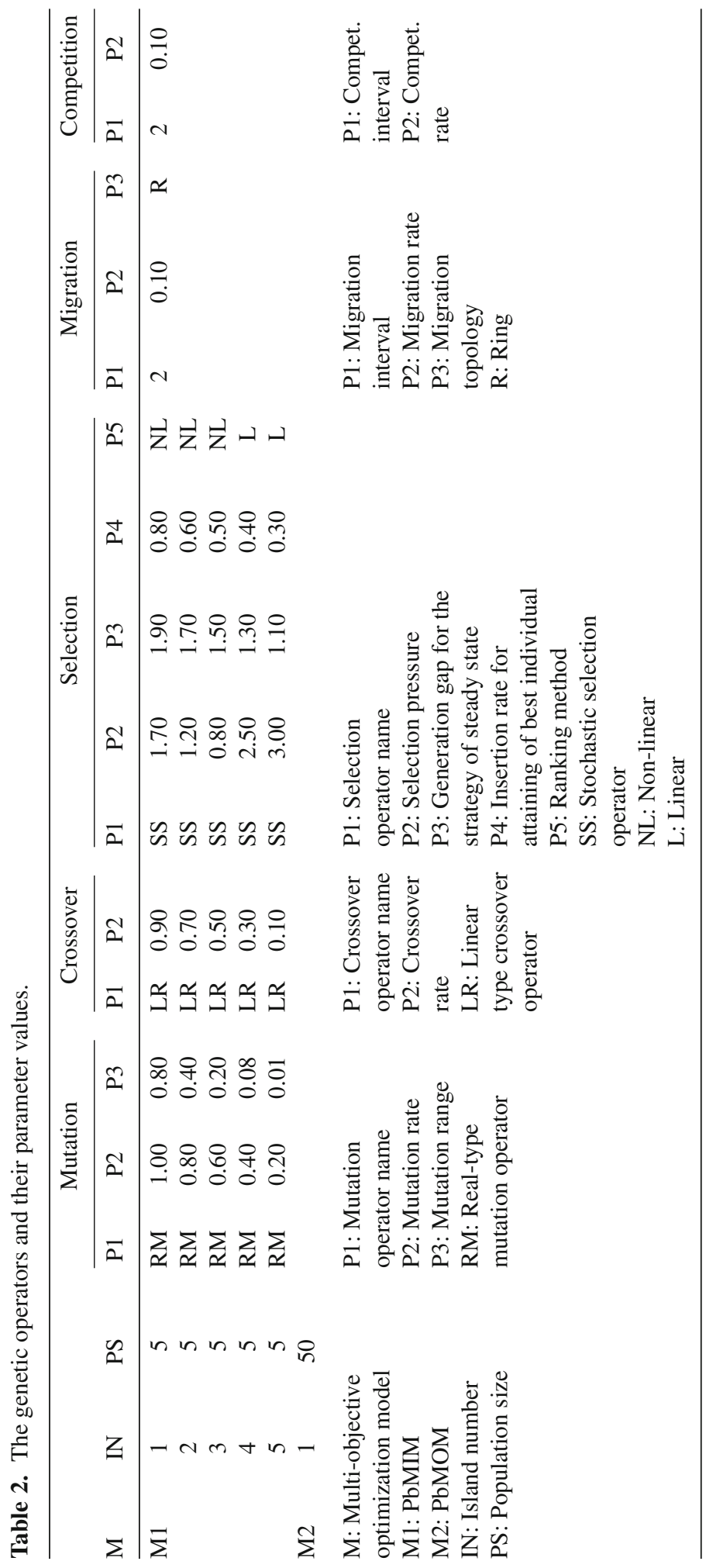


metrics, which are computed using the optimal designations obtained. The accuracy of these quality measuring metrics must be confirmed through statistical tests. Hence, a statistical test for the evaluation of these quality-measuring metrics must be performed with a certain level of confidence. Therefore, a reasonable approach is to obtain a true pareto front by runs of PbMOM and $\mathrm{PbMIM}$ in bigger and repeated generation numbers. Optimal designations obtained are utilized in computation of the quality-measuring metrics. Details of the quality-measuring metrics and related statistical tests are presented in following sub-sections.

\subsection{Quality-measuring metrics}

Differentiation in MOMs architecture makes it difficult to lay down the different aspects of MOMs' computational performance. Therefore, quality-measuring metrics play an important role in the accurate prediction of MOMs' computational performance. In this study, two fundamental quality-measuring metrics, inverted generational distance and spread are employed.

6.1a Inverted generational distance: Inverted generational distance (Igd) estimates the far of non-dominated solutions included in current pareto front generated by the proposed MOM, from those included in true pareto front (see Eq (2)).

$$
\mathrm{IGD}=\frac{\sqrt{\sum_{\mathrm{i}=1}^{\mathrm{n}} \mathrm{d}_{\mathrm{i}}^{2}}}{\mathrm{n}},
$$

where $n$ is number of non-dominated solutions found by proposed MOM and $d_{i}$ is Euclidian distance between each of these and nearest member of true pareto front. A lower value of Igd indicates a better approximation of current pareto front obtained to the true pareto front in terms of convergence.

6.1b Spread: This metric is used to measure an expanding spread exhibited by non-dominated solutions obtained and computed as,

$$
\mathrm{S}=\frac{\mathrm{d}_{\mathrm{f}}+\mathrm{d}_{1}+\sum_{\mathrm{i}=1}^{\mathrm{N}-1}\left|\mathrm{~d}_{\mathrm{i}}-\overline{\mathrm{d}}\right|}{\mathrm{d}_{\mathrm{f}}+\mathrm{d}_{\mathrm{l}}+(\mathrm{N}-1) * \overline{\mathrm{d}}},
$$

where $d_{i}$ is Euclidian distance between consecutive non-dominated solutions, $\bar{d}$ is mean of these distances, $d_{f}$ and $d_{l}$ are distances to extreme solutions of current pareto front. A lower $S$ value implies points out a better distribution among non-dominated solutions. In other words, it is implied that non-dominated solutions are located in different positions.

\subsection{Statistical tests}

After computing means and standard deviations of quality-measuring metrics, a statistical analysis is performed in a certain level of confidence. If a probability value resulted from a statistical test satisfies a user defined significance level, then it is said that distribution of PbMOM and $\mathrm{PbMIM}$ approximation set is acceptable.

The statistical analysis is performed using MATLAB (The MathWorks, Inc., Natick, MA, 2008) software. Firstly, the outcomes related to quality-measuring metrics are checked through 


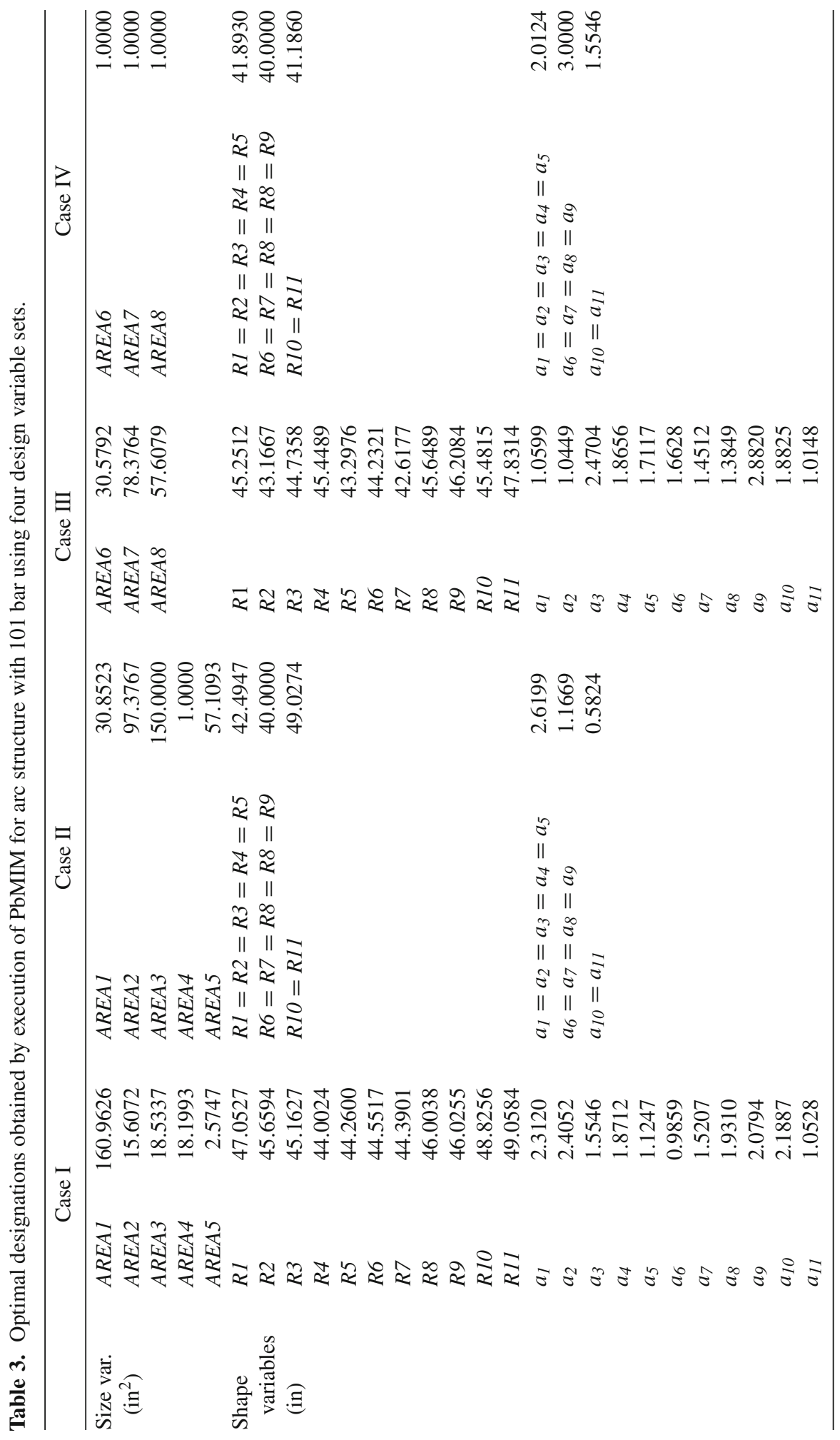




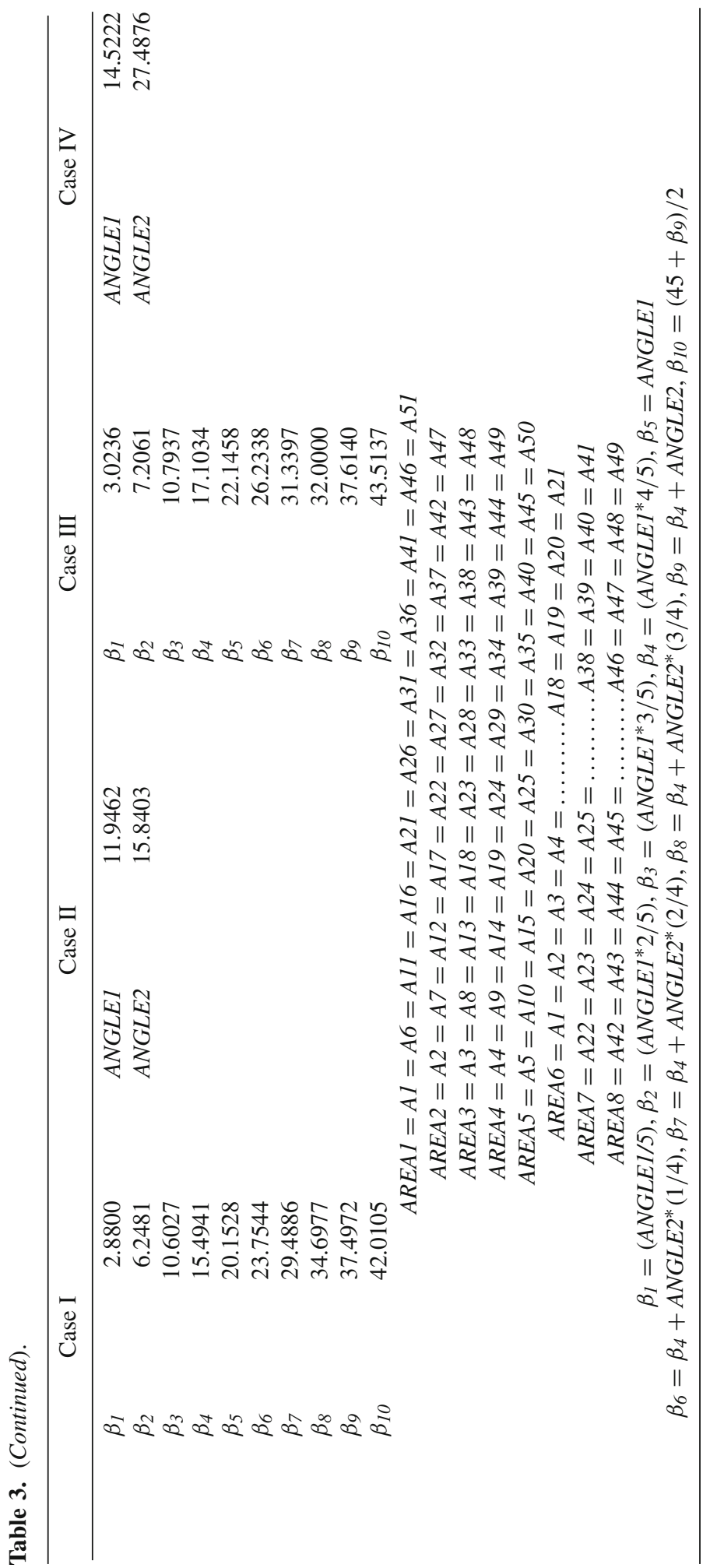


KolmogorovSmirnov test to inspect it whether to exhibit a normal distribution at 5\% (0.05) significance level. If the variance turns out to be homogeneous, an Anova test is performed; otherwise, a Welch test is utilized (Ortiz \& Walls 2003).

\section{Discussion of results}

The application examples are chosen among the real-world truss applications, each of which has a large number of truss members and a large span. The examples include an arch structure with 101 bars, a pyramid structure with 224 bars and a dome structure with 444 bars. The designs of these truss structures are optimized considering the multiple objectives without imposing any constraint. The design optimization of these truss structures is carried out by use of both PbMIM and $\mathrm{PbMOM}$ to compare their relative computational performances. For this purpose, considering the search methodology mentioned above, a true pareto front is obtained for each design example along with their current pareto fronts and random point sets. Then, the closeness of their current pareto fronts to the true pareto front is measured taking the quality-measuring metrics into account. These quality-measuring metrics is checked by the statistical testing procedure mentioned above. The successful multi-objective model is used for further examination of its optimal designations.

In order to consider the shape effect on design optimization, the size and shape-related design variables are simultaneously included in the optimal design of truss structures. Several combination sets of these design variables are devised for the size and shape-related design variables. A maximum joint deflection of 'max. span/300', a serviceability requirement prescribed by AISC (American Institute of Steel Construction), is also considered for evaluation of the optimal designations. The modulus of elasticity and density of the truss material is taken as $50 \times 10^{6} \mathrm{lb} / \mathrm{in}^{2}$ and $0.1 \mathrm{lb} / \mathrm{in}^{3}$.

The parameter set assigned in the arc-length method, namely 'number of increment', 'the number of iteration', and 'desired convergence degree', is taken, respectively, to be $(75,75$, 0.001 ) based on experience gained from several trial runs. Since the arc-length method is managed by an iterative-based computational procedure, the magnitude of load is adjusted at each

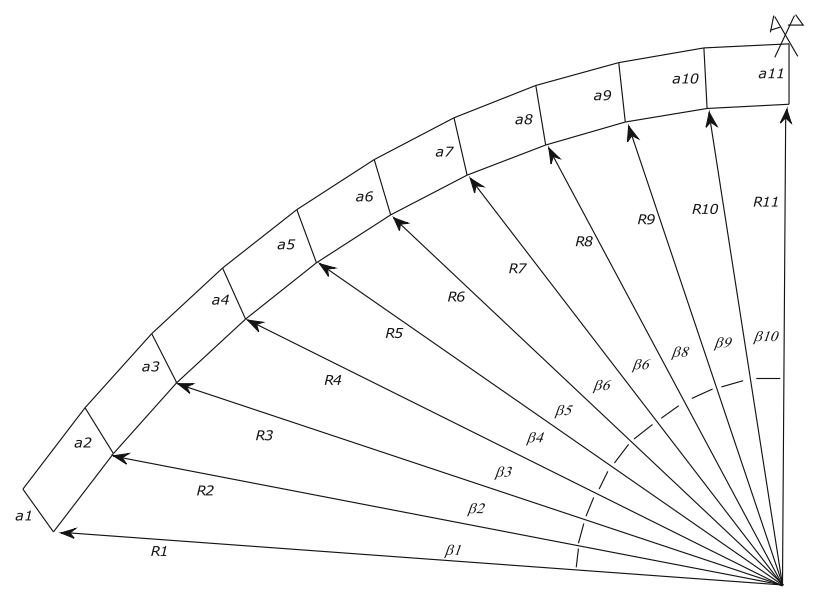

Figure 8. Geometrical parameters used to form arc shape. 

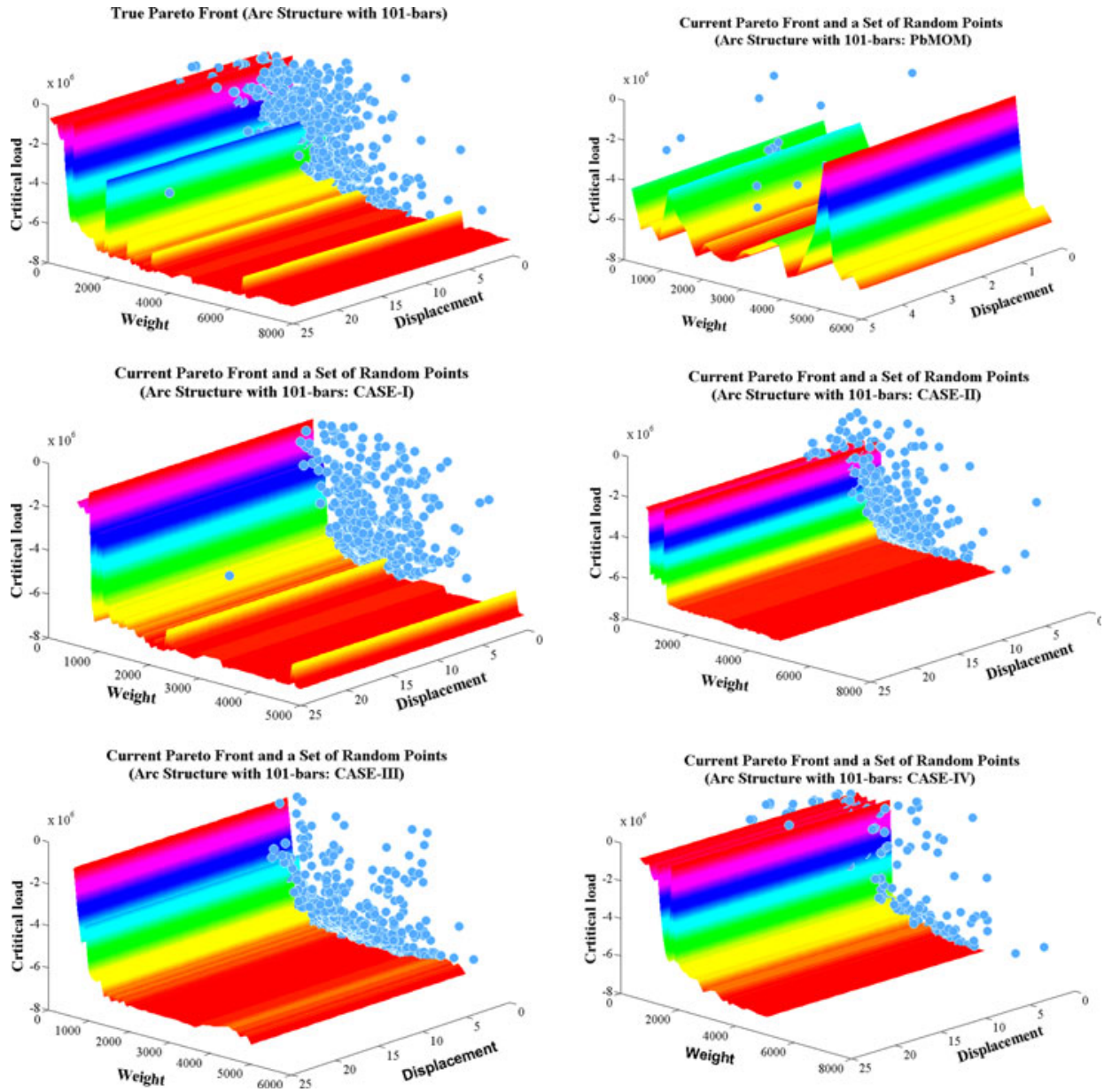

Figure 9. True pareto front and current pareto fronts obtained by PbMIM (containing case I-IV) and $\mathrm{PbMOM}$ for design example of arc structure with 101 bars.

Table 4. Statistical test results computed by use of quality-measuring metric values (arc structure with 101 bar).

\begin{tabular}{lccccccc}
\hline $\begin{array}{l}\text { Multi-objective } \\
\text { model }\end{array}$ & $\begin{array}{c}\text { Case } \\
\text { no. }\end{array}$ & $\begin{array}{c}\text { Mean } \\
\text { (spread) }\end{array}$ & $\begin{array}{c}\text { Std } \\
\text { (spread) }\end{array}$ & $\begin{array}{c}\text { P } \\
\text { (Welch test) }\end{array}$ & $\begin{array}{c}\text { Mean } \\
\text { (Igd) }\end{array}$ & $\begin{array}{c}\text { Std } \\
\text { (Igd) }\end{array}$ & $\begin{array}{c}\text { P } \\
\text { (Welch test) }\end{array}$ \\
\hline PbMIM & 1 & 0.840 & 0.067 & & 0.145 & 0.086 & \\
& 2 & 0.867 & 0.059 & & 0.210 & 0.171 & \\
& 3 & 0.854 & 0.080 & 0.930 & 0.199 & 0.069 & 0.518 \\
PbMOM & 4 & 0.873 & 0.082 & & 0.218 & 0.108 & \\
\hline
\end{tabular}

Mean: average of spread and Igd. Std: standard deviation of spread and Igd 
Table 5. Genetic output obtained by execution of PbMIM for arc structure with 101 bar (see table 3).

\begin{tabular}{|c|c|c|c|c|c|}
\hline & & Case I & Case II & Case III & Case IV \\
\hline Min. weight (lb) & (Fitness fun. 1) & 1017.8264 & 2690.9995 & 1974.8400 & 32.8973 \\
\hline Min disp (in) & (Fitness fun. 2)* & 0.2180 & 0.9026 & 0.3190 & 5.6317 \\
\hline Max. crit. load (lb) & (Fitness fun. 3) & 2044363.4099 & 1066399.8177 & 1597224.3750 & 696366.7552 \\
\hline No. of increments & & 19 & 20 & 25 & 23 \\
\hline No. of iteration for last in & icrement & 10 & 12 & 14 & 12 \\
\hline Mean fitness Values (lb) & Fitness fun 1 & 2307.2134 & 2025.6656 & 2631.5167 & 1123.2807 \\
\hline & Fitness fun 2 & 2.4115 & 2.8443 & 2.9010 & 2.7825 \\
\hline & Fitness fun 3 & 1883125.5520 & 1873942.1765 & 2242967.7266 & 1422018.8589 \\
\hline Standard deviation & Fitness fun 1 & 839.2990 & 1389.0367 & 1282.8348 & 1599.1873 \\
\hline of fitness values & Fitness fun 2 & 2.0594 & 1.7065 & 1.7740 & 2.2449 \\
\hline & Fitness fun 3 & 851568.5236 & 897190.8531 & 899561.2363 & 937744.2370 \\
\hline
\end{tabular}

*Computed at apex of arc structure

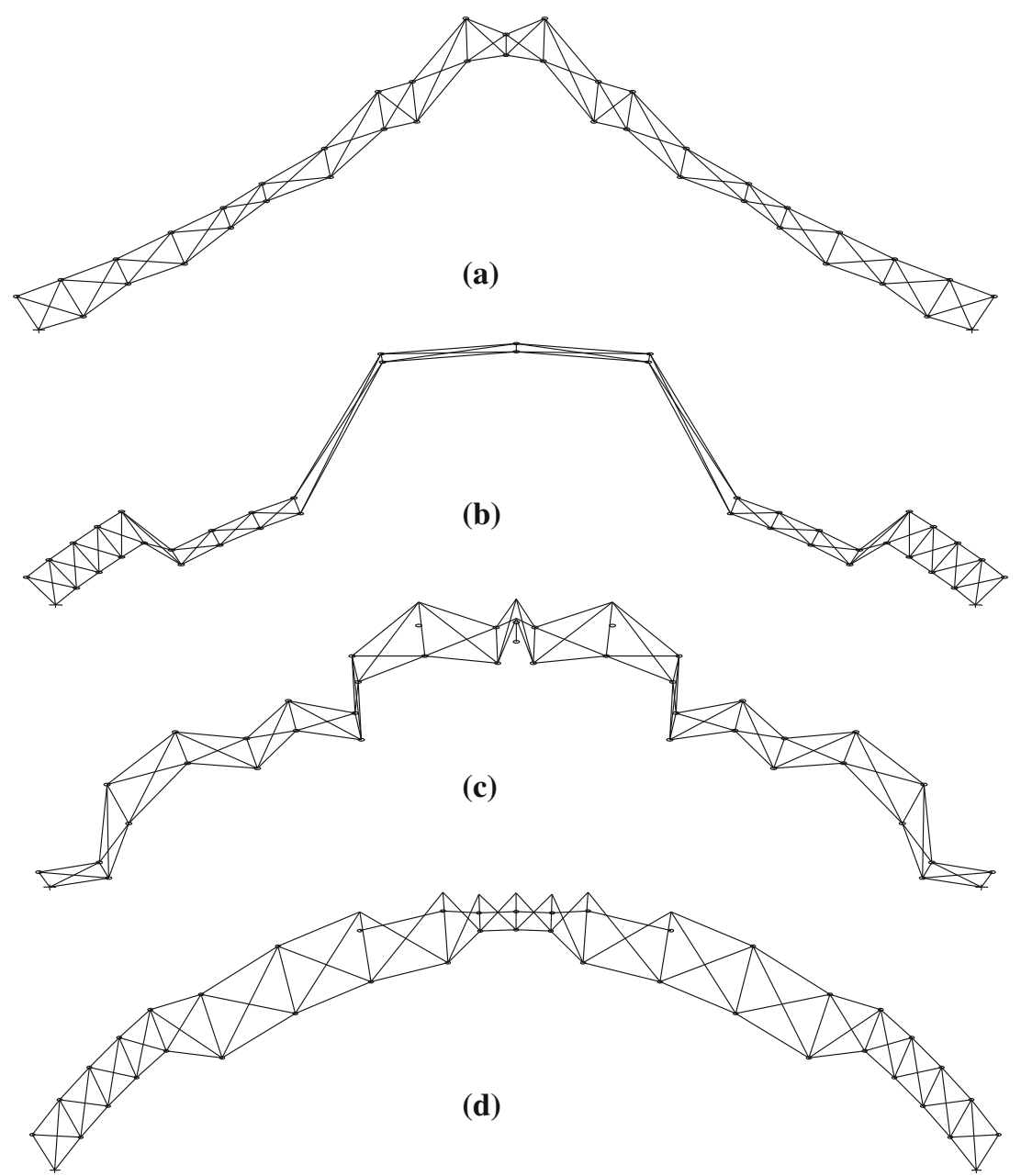

Figure 10. Optimal shapes of arc structure with 101 bar obtained by use of design variables represented by case I $(\mathbf{a})$, case II $(\mathbf{b})$, case III $(\mathbf{c})$, case IV $(\mathbf{d})$. 


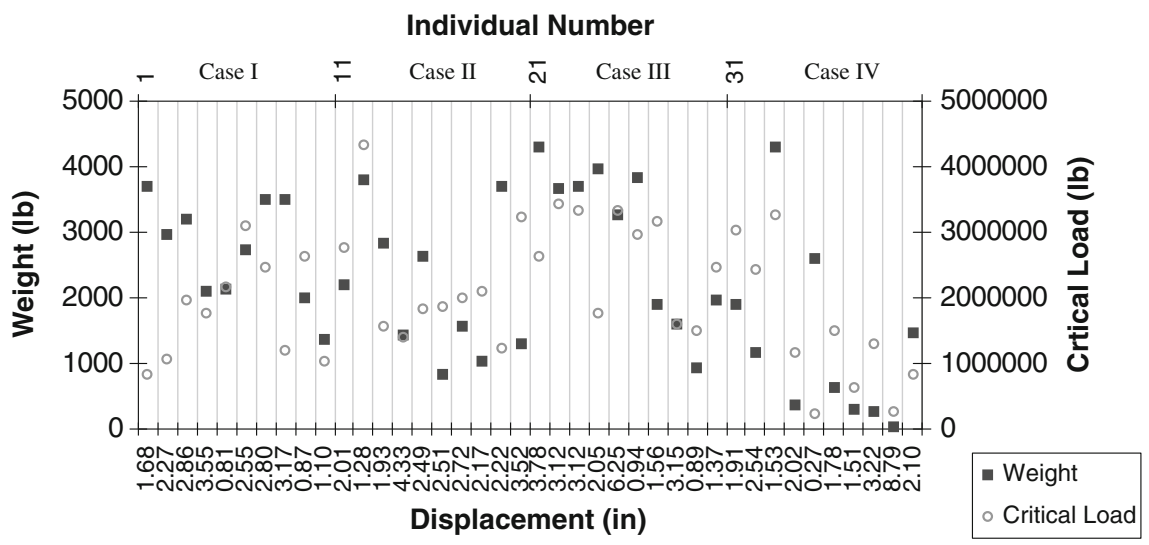

Figure 11. Variation of displacement and critical load at apex with weight of arc structure with 101 bar.

iteration according to the incremental procedure (see section 2). Therefore, the magnitudes of loads imposed to truss examples are not presented.

The computational optimization involving the optimization procedure and the structural analysis is coded within MATLAB software.

\subsection{Application example 1: Arc structure with 101 bar}

This arch structure was firstly used to test the computational performance of Crisfield' arc-length method (Crisfield 1997). In this study, it is tackled to both verify the accuracy of proposed arc-length method and demonstrate the efficiency of PbMIM and PbMOM with various design variable sets. This truss has a vertical load at the apex (figure $3 \mathrm{~b}$ ).

The cross-sectional area of each member, denoted by $A$ is used to represent 'size-related design variable'. The 'shape-related design variables' are the 'radius of arch segments' $R$, the 'length of radial member of the arch' $a$ and the 'angle between two sequential arch segments' $\beta$. Four different sets of design variables are represented by Case I-IV (table 3 ). The shaperelated design variables AREA1-AREA 8 are also presented in table 3 . The left symmetric part

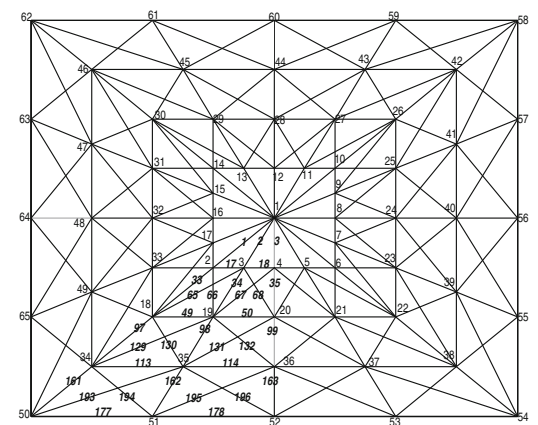

(a)

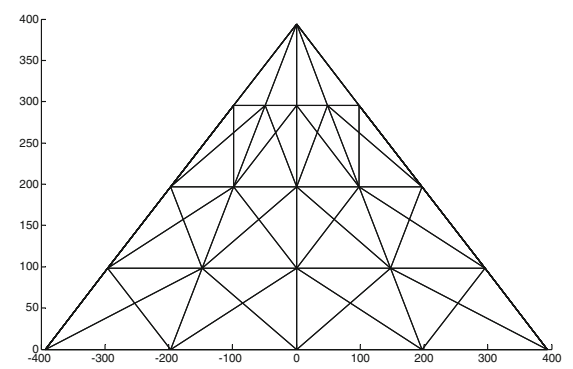

(b)

Figure 12. Mesh (a) and geometry attributes (b) of pyramid structure with 224 bar. 


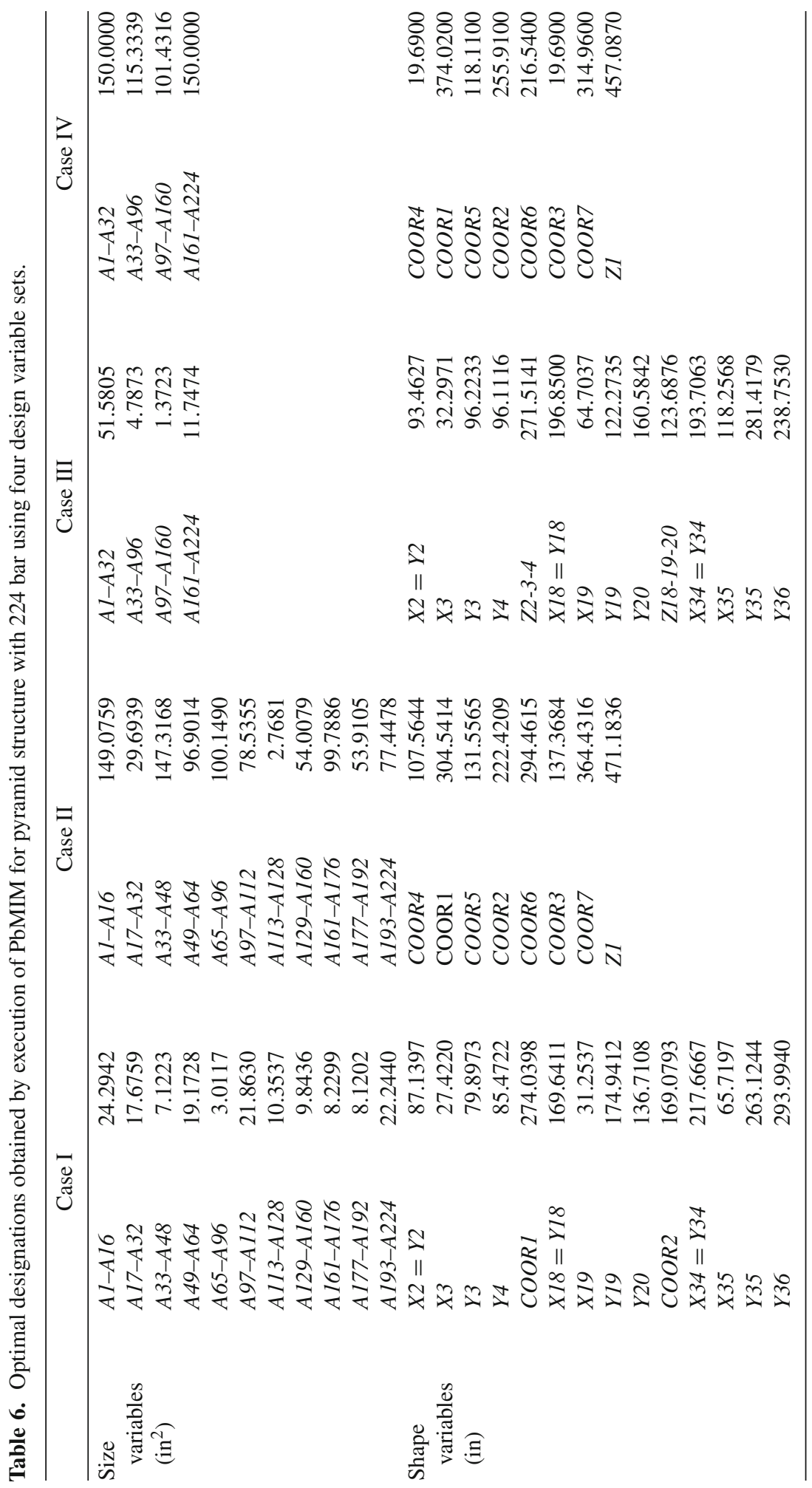




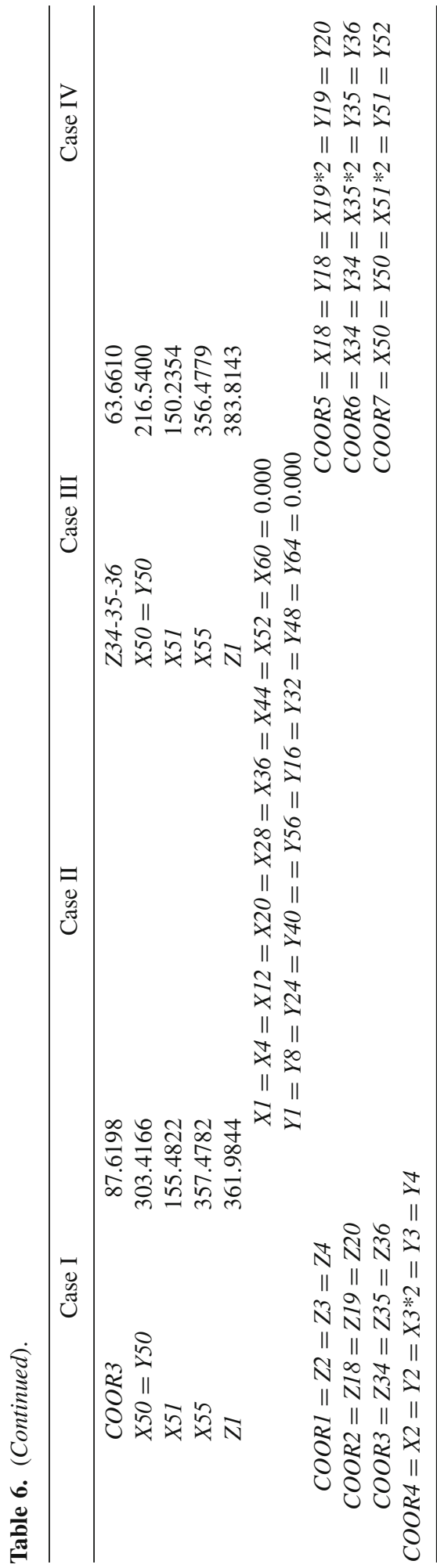



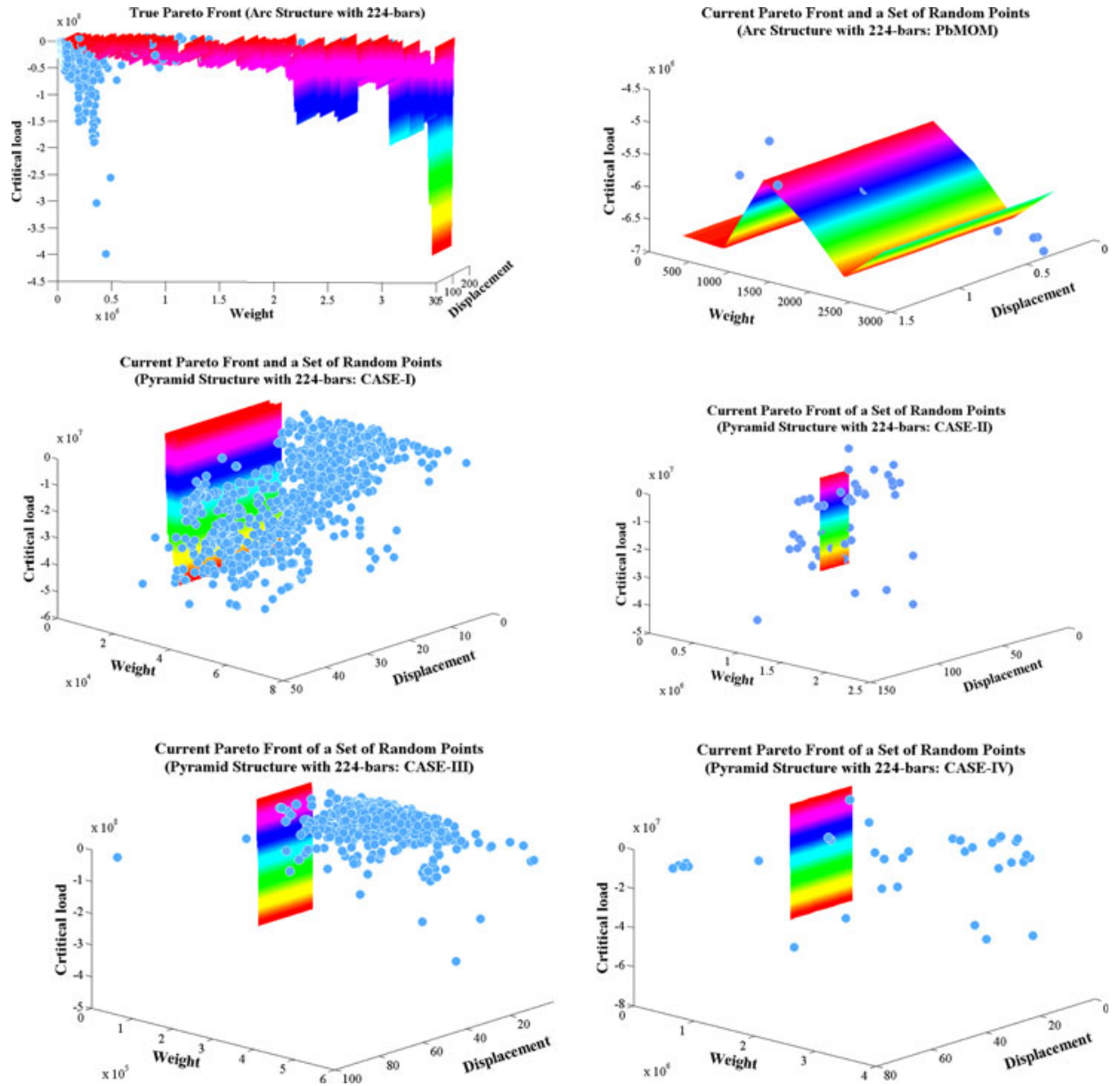

Figure 13. True pareto fronts and random point sets for design example of pyramid structure with 224 bars.

Table 7. Statistical test results computed by use of quality measuring metric values (arc structure with 224 bar).

\begin{tabular}{lccccccc}
\hline $\begin{array}{l}\text { Multi-objective } \\
\text { model }\end{array}$ & $\begin{array}{c}\text { Case } \\
\text { no. }\end{array}$ & $\begin{array}{c}\text { Mean } \\
\text { (spread) }\end{array}$ & $\begin{array}{c}\text { Std } \\
\text { (spread) }\end{array}$ & $\begin{array}{c}\text { P } \\
\text { (Welch test) }\end{array}$ & $\begin{array}{c}\text { Mean } \\
(\text { Igd) }\end{array}$ & $\begin{array}{c}\text { Std } \\
\text { (Igd) }\end{array}$ & $\begin{array}{c}\text { P } \\
\text { (Welch test) }\end{array}$ \\
\hline PbMIM & 1 & 0.821 & 0.080 & & 0.089 & 0.057 & \\
& 2 & 0.843 & 0.083 & & 0.127 & 0.108 & \\
& 3 & 0.827 & 0.037 & 0.338 & 0.115 & 0.075 & 0.145 \\
PbMOM & 4 & 0.880 & 0.070 & & 0.155 & 0.071 & \\
\hline
\end{tabular}

Mean: average of spread and Igd. Std: standard deviation of spread and Igd 
of this arch structure is presented to display both size and shape-related design variables of arch structure (figure 8). The (half) arch includes 10 segments, each of which contains eleven $R$ (denoted by $R 1-R 11$ ), ten $\beta$ values (denoted by $\beta 1-\beta 10$ ), eleven $a$ values (denoted by $a 1-a 11$ ), and two independent angle values ANGLE1 and ANGLE2 (see Appendix A for the details on computation of nodal coordinates).

In order to evaluate the computational performance of PbMIM and PbMOM, their true pareto front and current pareto fronts obtained are presented in figure 9. Also, a statistical output obtained by computing the values of quality-measuring metrics is tabulated in table 4 . Considering table 4, there is no considerable difference among spread and Igd values of PbMIM and $\mathrm{PbMOM}$ due to satisfying condition as $(\mathrm{p}>0.050)$. Furthermore, the Spread and Igd values of PbMIM are lower than PbMOM. Therefore, the quality degree of optimal designations corresponding to $\mathrm{PbMIM}$ is higher than $\mathrm{PbMOM}$.

Particularly, the success order of four cases obtained by use of PbMIM is Case I, III, II and IV. In this regard, some designations obtained by PbMIM are picked from the related cases to carry out a further observation about them. Case 1 achieves to obtain a better optimal designation with a displacement of $0.2180 \mathrm{in}$. at node 1 along the x-direction and a critical load of $2044363.4099 \mathrm{lb}$ (table 5) thereby satisfying the serviceability requirement prescribed by AISC $(34.901 * 2 / 300=0.2327)$. It is apparent that the poorest fitness values set $(32.8973 \mathrm{lb}, 5.6317$ in. and 696366. $7552 \mathrm{lb}$ ) corresponds to Case IV (see table 5). Thus, final shape of arch structure corresponding to Case IV is obtained to be similar to its initial shape (figure 10d). Considering figure 11 and table 5, it can be said that the convergence degree of optimal designations corresponding to Case IV is lower than Case I.

Examining the arch member cross-sectional areas, it is recognized that there is a direct relation between the cross-sectional areas of diagonal members and the quality degree of optimal solution. In Case I, cross-sectional area values of diagonal members (160.9626, 18.5337, and 18.993 for members collected in the group called 'AREA1-AREA3') are higher than cross-sectional area values of the remaining members (15.6072 and 2.5747 for members collected in the group called 'AREA4-AREA5'). Furthermore, member cross-sectional areas have a tendency to increase as they approach the arch support points. Same results are observed for Case II (table 3).

Table 8. Genetic output obtained by execution of PbMIM for pyramid structure with 224 bar (see table 6).

\begin{tabular}{lccccc}
\hline & & Case I & Case II & Case III & Case IV \\
\hline Min. weight (lb) & (Fitness fun. 1) & 42284.5605 & 282165.9660 & 34624.2193 & 442358.8447 \\
Min. disp. (in) & (Fitness fun. 2) & 0.3075 & 18.1748 & 20.7085 & 3.475 \\
$\begin{array}{l}\text { Max. crit. load (lb) } \\
\text { No. of increments }\end{array}$ & (Fitness fun. 3) & 2160787.2328 & 27135361.7271 & 26506061.4521 & 15580738.5066 \\
$\begin{array}{l}\text { No. of iteration for last increment } \\
\text { Mean of fitness }\end{array}$ & 6 & 66 & 44 & 32 \\
\multicolumn{1}{l}{ values } & Fitness fun 1 & 39228.1598 & 827420.1266 & 208118.1808 & 1741278.4138 \\
Standard deviation & Fitness fun 2 & 11.5427 & 56.9995 & 6.8014 & 25.9820 \\
\multicolumn{1}{l}{ of fitness values } & Fitness fun 1 & 4240749.9747 & 14083218.3003 & 23104780.0177 & 12276148.8053 \\
& Fitness fun 2 & 6.0596 & 335190.5445 & 68211.8514 & 1074230.8200 \\
& Fitness fun 3 & 8407213.0250 & 10888350.1210 & 22879827.6520 & 9158817.0309 \\
\hline
\end{tabular}

*Computed at Apex of Arc Structure 

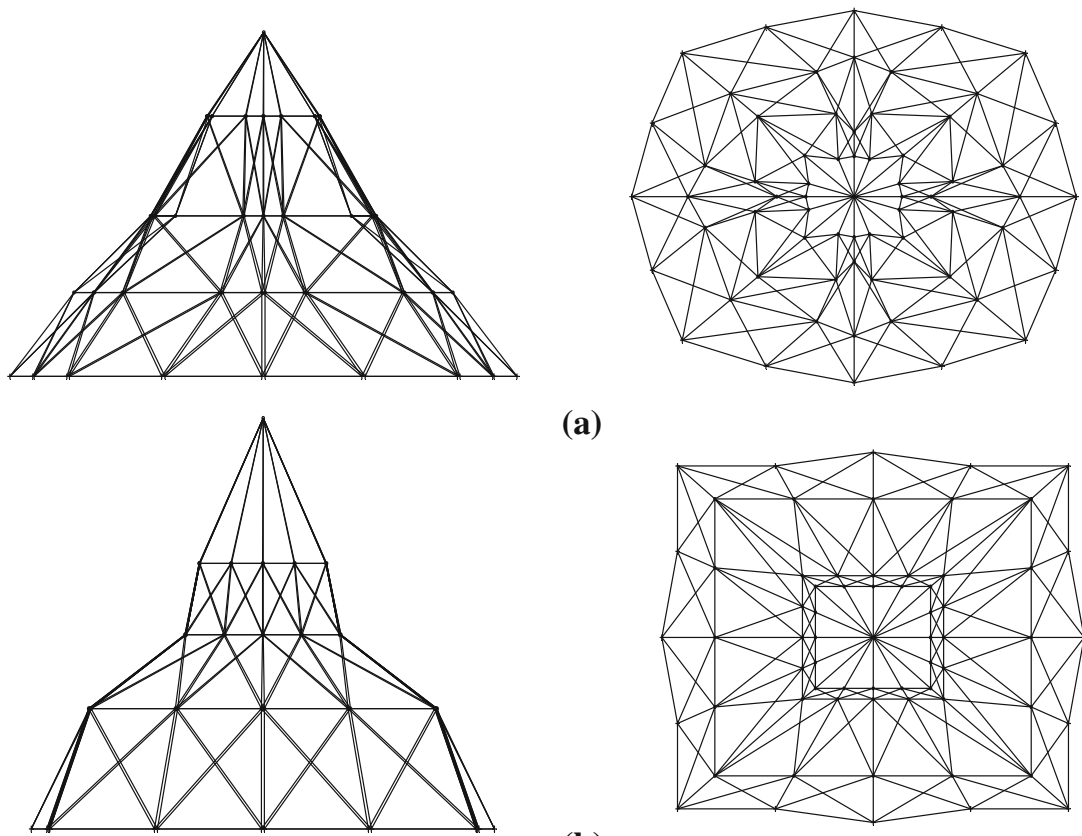

(a)
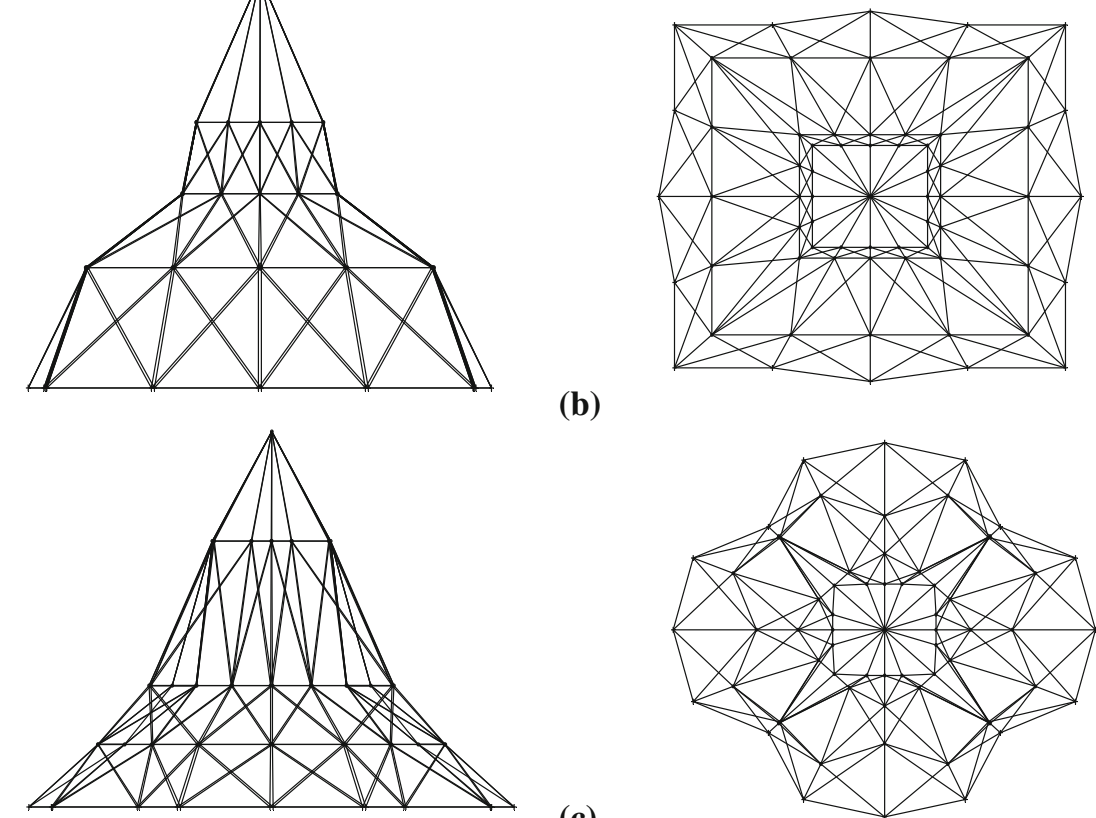

(c)
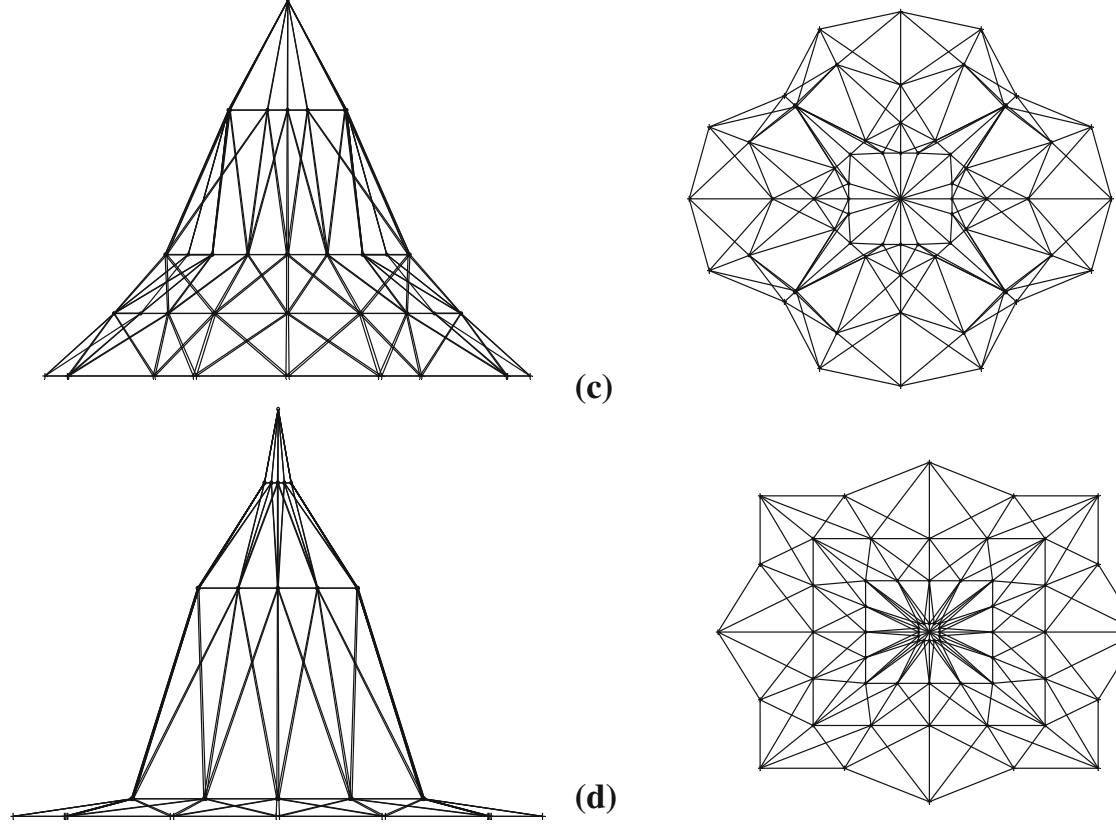

(b)

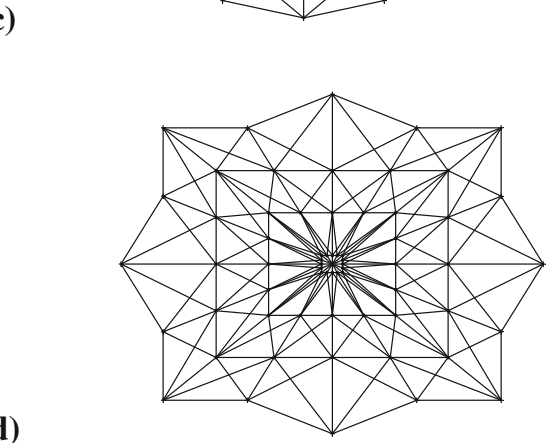

Figure 14. Optimal shapes of pyramid structure with 224 bar obtained by use of design variables represented by case I (a), case II (b), case III $(\mathbf{c})$, case IV $(\mathbf{d})$. 


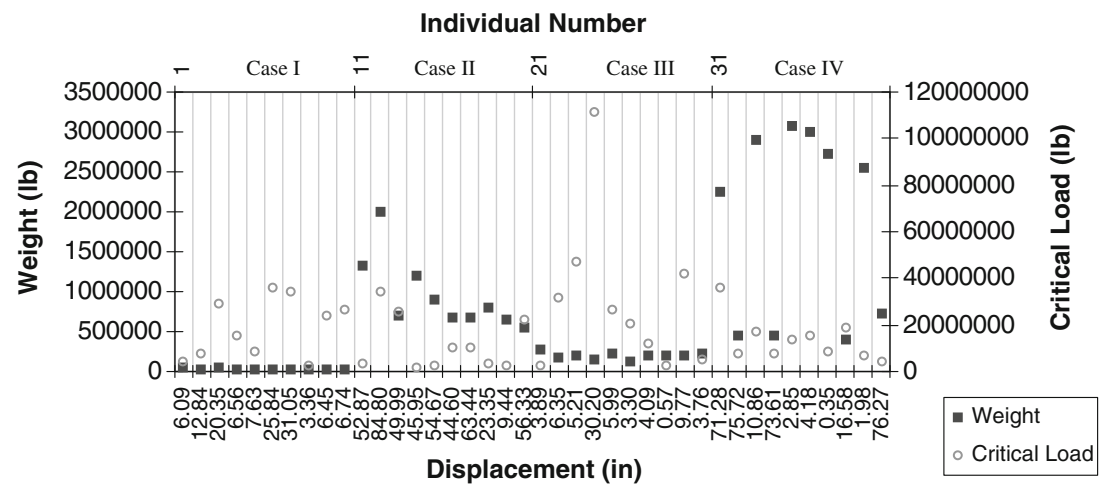

Figure 15. Variation of displacement and critical load at apex with weight of pyramid structure with 224 bar.

\subsection{Application example 2: Pyramid structure with 224 bar}

The pyramid structure has 224 bars. It is originally a single-layer-latticed pyramid (figures $12 \mathrm{a}$ and 12b) (Hasancebi \& Erbatur 2002). This four-storey pyramid with equal levels is loaded both by two horizontal loads in two $\mathrm{x}$ and $\mathrm{y}$ directions and a vertical load at its apex. In order to preserve the pyramid form for architectural and aesthetic purposes, nodes located on symmetry axes are restricted to move along these axes. For this purpose, the position of nodes 52, 56, 60 and 64 are fixed to 393.70 in. Equality of certain nodal coordinates is provided by the coordinate parameters, denoted by COOR1-COOR7. The size and shape-related design variables are summarized in table 6.

In order to evaluate the computational performance of PbMIM and PbMOM, their true pareto front and current pareto fronts obtained are presented in figure 13. Also, a statistical output obtained by computing the values of quality-measuring metrics is tabulated in table 7 . Considering table 7, it can be said that there is no considerable difference among spread and Igd values of $\mathrm{PbMIM}$ and $\mathrm{PbMOM}$ for satisfying the required condition as $(\mathrm{p}>0.050)$. Furthermore, the Spread and Igd values of PbMIM are lower than PbMOM. Therefore, the quality degree of optimal designations corresponding to PbMIM is higher than PbMOM.

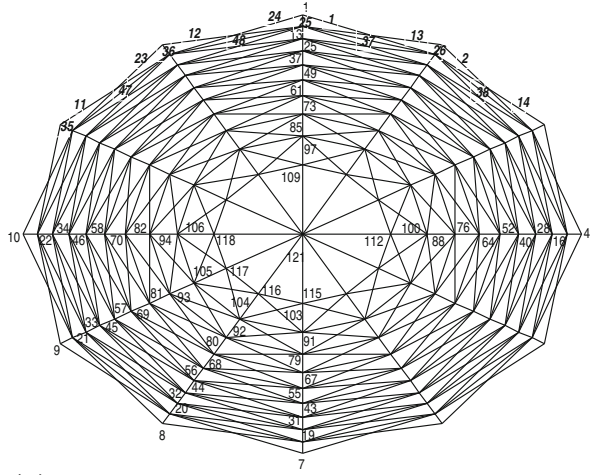

(a)

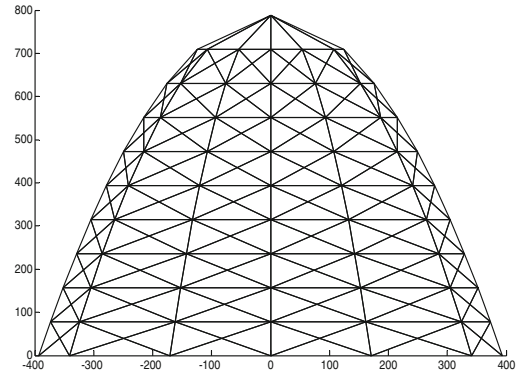

(b)

Figure 16. Mesh (a) and geometry, (b) attributes of dome structure with 444 bar. 


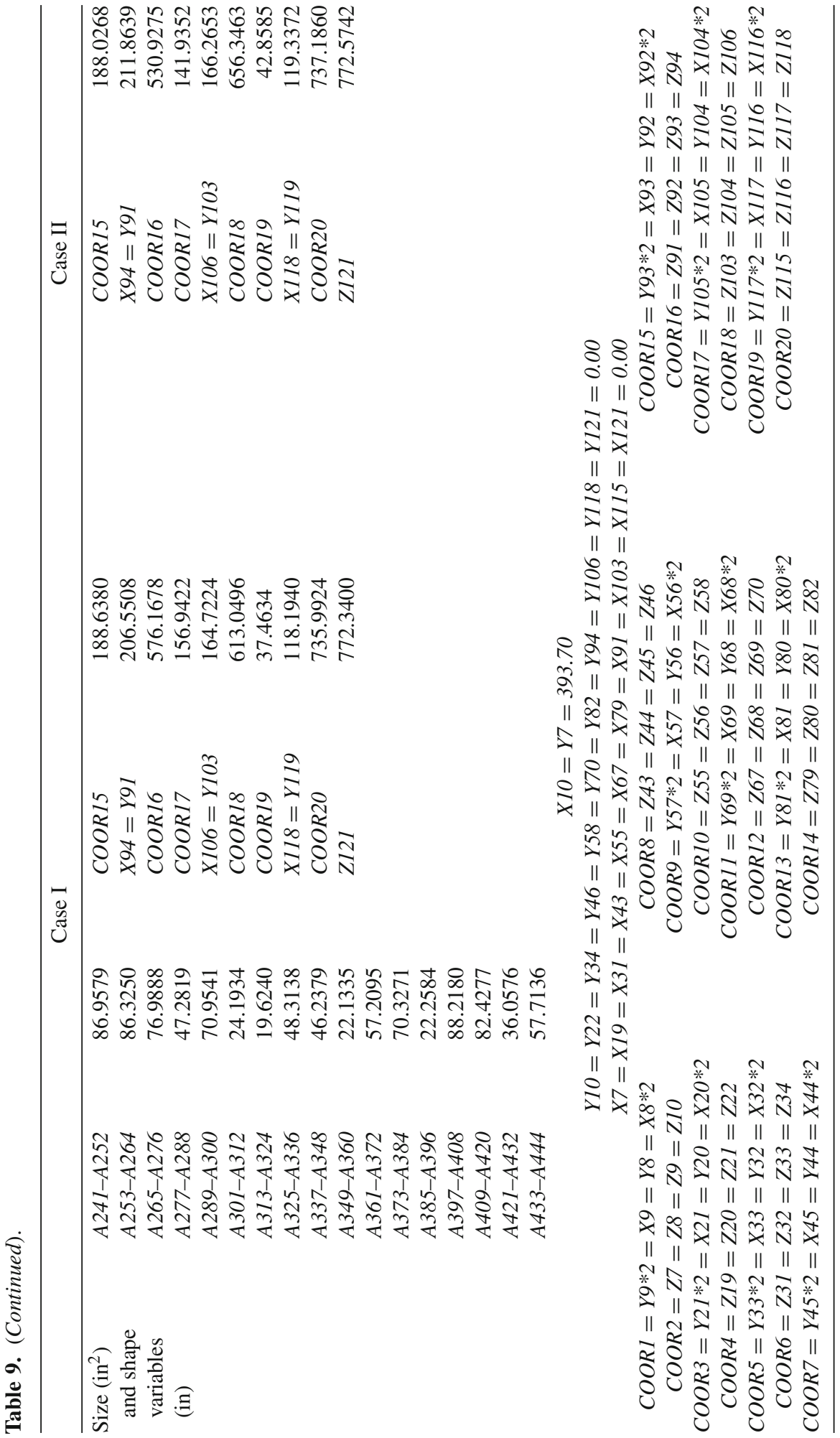



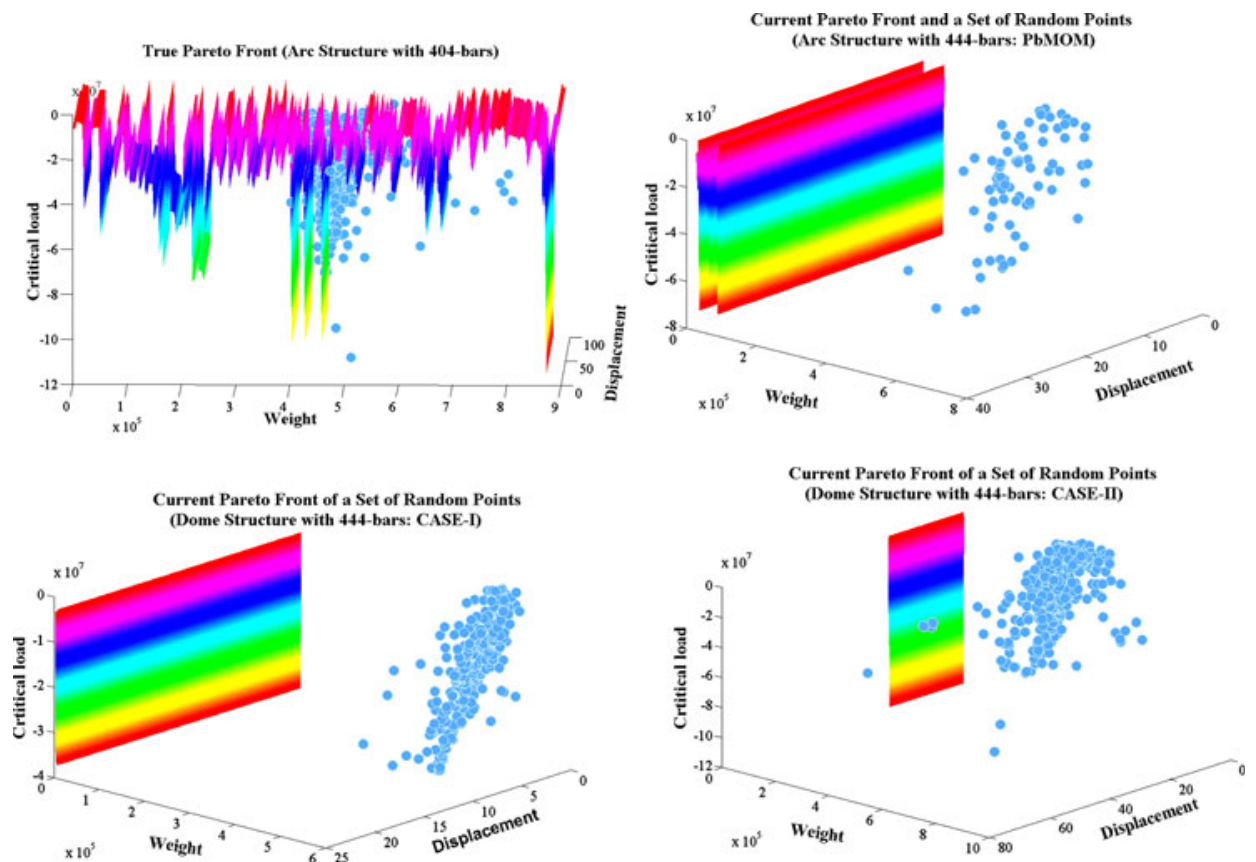

Figure 17. True pareto fronts and random point sets for design example of dome structure with 444 bars.

Table 10. Statistical test results computed by use of quality measuring metric values (arc structure with 444 bar).

\begin{tabular}{lccccccc}
\hline $\begin{array}{l}\text { Multi-objective } \\
\text { model }\end{array}$ & $\begin{array}{c}\text { Case } \\
\text { no. }\end{array}$ & $\begin{array}{c}\text { Mean } \\
\text { (spread) }\end{array}$ & $\begin{array}{c}\text { Std } \\
\text { (spread) }\end{array}$ & $\begin{array}{c}\text { P } \\
\text { (Welch test) }\end{array}$ & $\begin{array}{c}\text { Mean } \\
\text { (Igd) }\end{array}$ & $\begin{array}{c}\text { Std } \\
\text { (Igd) }\end{array}$ & $\begin{array}{c}\text { P } \\
\text { (Welch test) }\end{array}$ \\
\hline PbMIM & 1 & 0.901 & 0.076 & & 0.155 & 0.071 & \\
& 2 & 0.880 & 0.070 & 0.746 & 0.153 & 0.115 & 0.657 \\
PbMOM & 1 & 0.912 & 0.058 & & 0.220 & 0.113 & \\
\hline
\end{tabular}

Mean: average of spread and Igd. Std: standard deviation of spread and Igd

Table 11. Genetic output obtained by execution of PbMIM for dome structure with 444 bar (see table 9).

\begin{tabular}{lccc}
\hline & & Case I & Case II \\
\hline Min. weight (lb) & (Fitness fun. 1) & 422251.0074 & 476924.9852 \\
Min. disp. (in) & (Fitness fun. 2)* & 1.5354 & 0.2522 \\
Max. crit. load (lb) & (Fitness fun. 3) & 5723679.9033 & 1300238.2772 \\
No. of increments & & 11 & 5 \\
No. of iteration for last increment & & 8 & 10 \\
Mean of fitness values (lb) & Fitness fun 1 & 487087.6646 & 475162.3599 \\
& Fitness fun 2 & 33.0835 & 11.3302 \\
& Fitness fun 3 & 42267629.9753 & 22941818.8341 \\
Standard deviation of fitness values & Fitness fun 1 & 72168.9213 & 43863.7239 \\
& Fitness fun 2 & 10.7712 & 7.2594 \\
& Fitness fun 3 & 26609538.1877 & 16635233.4047 \\
\hline
\end{tabular}

*Computed at apex of arc structure 
Particularly, the success order of four cases obtained by use of PbMIM is Case I, III, II and IV. In this regard, some designations obtained by PbMIM are picked from these cases to carry out a further observation about them. Compared to the other cases, Case I succeed in obtaining better optimal designation with a lower displacement value of 0.3075 in. satisfying the serviceability requirement prescribed in AISC specification $(393.7 * 2 / 300=2.6247)$. However, critical load value corresponding to Case I, 2160787.2328 is poorest compared to a critical load value set of Case II, III and IV (27135361.7271, 26506061.4521 and 15580738.5066) (table 8). It is shown that the final shape of pyramid structure corresponding to Case I has a higher apex height (figure 14). It is clear that computational performance of Case I is higher than the other ones considering the decreased standard deviation value set of fitness values (4961.4366, 6.0596 and 8407213.0250) (table 8) and the higher convergence degree of weight and critical load (figure 15).

The relation between pyramid member cross-sectional areas is also investigated. After a careful examination of pyramid member cross-sectional areas corresponding to Case I (table 6), it is noticed that the diagonal member cross-sectional areas set $(24.2942,21.8630$ and 22.4440 for members ' $1-16$ ', '98-112' and '193-224') are larger than the other member cross-sectional areas set $(17.6759,7.1223,19.1728$...etc. for members '17-32', '33-48', '49-64'...etc.). Pyramid member cross-sectional areas are increased towards pyramid support points (table 6).

\subsection{Application example 3: Dome structure with 444 bar}

A dome structure with 444 bar is considered to evaluate the computational performance of $\mathrm{PbMIM}$ and $\mathrm{PbMOM}$ with respect to an increased number of truss member and severe loading
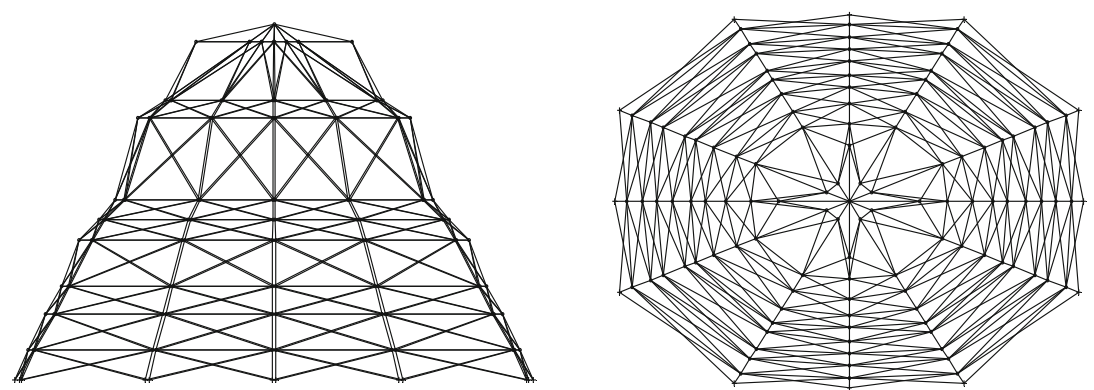

(a)
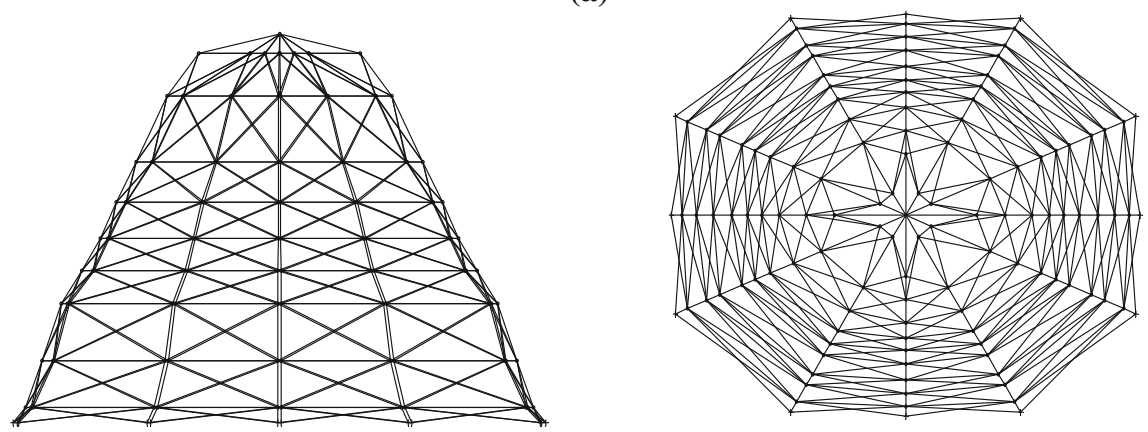

(b)

Figure 18. Optimal shapes of dome structure with 444 bar obtained by use of design variables represented by case I $(\mathbf{a})$, case II $(\mathbf{b})$. 
conditions (Lamberti \& Pappalettere 2004). It has vertical loads at node 121 and the other free nodes, respectively (see the mesh and geometry attributes of dome structure in figure 16).

While size-related design variables are represented by dome member cross-sectional areas, nodal coordinates are employed for shape-related design variables. Taking the symmetry of dome into account, all nodes collected into groups (COOR1-COOR20) are listed for the quarter part of entire dome structure (table 9). Diagonal and horizontal members at each storey are collected into either separate groups or single group. In this regard, size and shape-related design variables are collected into two combination sets notated by Case I and II (see linked members in table 9).

The true pareto front and current pareto fronts of PbMIM and PbMOM obtained are presented in figure 17. Also, a statistical output obtained by computing the values of quality-measuring metrics is tabulated in table 10. Considering table 10, it can be said that there is no considerable difference among spread and Igd values of PbMIM and PbMOM considering the required condition ( $\mathrm{p}>0.050$ ). Furthermore, the spread and Igd values of PbMIM are lower than PbMOM. Therefore, the quality degree of optimal designations corresponding to PbMIM is higher than PbMOM. Particularly, the success order of two cases obtained by use of PbMIM is Case II and I. In this regard, some designations obtained by PbMIM are picked from these cases to carry out a further observation about them.

The genetic output is listed in table 11. Distinguished from the preceding two examples, Case II achieves to obtain the highest quality of optimal design (476924.9852, 0.2522 and 1300238.2772) satisfying serviceability requirement prescribed in AISC specification $(400 * 2 / 300=2.6667)$ for node 121 in $\mathrm{z}$ direction. The final shapes obtained for Cases I and II are presented in figure 18. The success of Case II is confirmed by lower standard deviation values (see table 11) and smaller displacement-weight values but higher critical load value (figure 19).

It is clear that there is a relation between diagonal arch member cross-sectional areas and quality degree of optimal designations. In Case I, cross-sectional area values of diagonal arch member (131.2317, 102.2929 for members ' $1-12$ ' and '13-24') are generally higher than other arch member cross-sectional area set (77.1898 and 34.7586 for members '25-36' and '37-48') (see table 9). Moreover, it is seen that the member cross-sectional areas located in the bottom

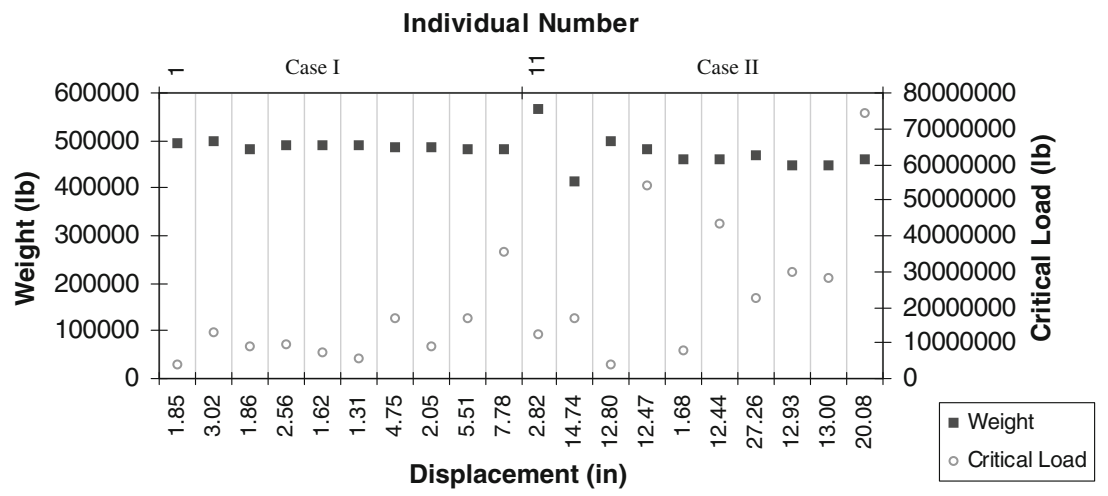

Figure 19. Variation of displacement and critical load at apex with weight of dome structure with 444 bar. 
part of the dome are larger than the member cross-sectional areas located in upper part close to the apex point (table 9).

\section{Conclusion}

In this work, the effect of global stability on design optimization of truss structure is investigated using multiple objective functions. For this purpose, two multi-objective optimization models, the pareto-ranking based multi-objective optimization model (PbMOM) and the pareto-ranking based multi-objective island model (PbMIM) are utilized to optimize the design of the real-world planar and spatial truss structures using different combinations of size and shape-related design variables. In order to compute the nonlinear critical load, arc-length method is employed and improved to estimate the nonlinear critical load with an increased degree of accuracy thereby implementing an eigenvalue analysis into its iteration mechanism.

The following observations are drawn from this work:

(i) The computational performances of PbMIM and PbMOM are compared by use of two quality-measuring metrics, Spread and Igd. Furthermore, a statistical test is performed to asses the accuracy of these quality-measuring metrics. Although the population size utilized by $\mathrm{PbMOM}$ is twice the size of PbMIM's population, it is shown that PbMIM is more efficient optimization tool for optimal design of geometrically-nonlinear truss structures than PbMOM.

(ii) An increase in the number of members and joints linked causes to decrease the variety in optimal designations. Thus, the quality degree of optimal designations becomes poorer.

(iii) Diagonal truss members of truss structure have a major role in maximization of critical load. In this regard, it is shown that cross-sectional areas of diagonal truss members corresponding to optimal designations are larger than the other truss members.

(iv) Considering the optimal designations, it is displayed that member cross-sectional areas located around truss support points are larger than the other part of truss structures.

(v) It is displayed that PbMIM has a capability of generating feasible designations for even more large and complex design spaces.

(vi) This study brings a new look at the nonlinearity effect on a simultaneously size and shape optimization of truss structures. Therefore, proposed optimal design procedure deserves more attention. The computational procedures of PbMIM are managed by the probabilistic transition rules. Therefore, size and shape-related design variables are randomly generated. Hence, although it is demonstrated that PbMIM achieves to generate feasible designations, the number of feasible designations is decreased when truss shape obtained is not practically applicable.

The future study will be improved by completing the following lacunae for design optimization of geometrically nonlinear truss structures.

- Shape-related-design variables will be adjusted according to a practically-applicable-truss shape, for example a circle, ellipse, a line with a predefined angle, etc. instead of a random adjustment. Hence, the feasible solutions are correspondingly increased.

- The branched points located on sub-path switched from critical load will be considered to evaluate their effect on the optimality degree.

- The penalization process will be improved to increase the number of feasible designations and the quality of optimal designations. 
Appendix A. Computation of nodal coordinates.

\begin{tabular}{|c|c|c|}
\hline \multirow{2}{*}{$\begin{array}{l}\text { Node } \\
\text { number }\end{array}$} & \multicolumn{2}{|c|}{$\begin{array}{c}\text { Matlab expressions used to compute nodal coordinates } \\
\text { of arc structure with } 101 \text { bar }\end{array}$} \\
\hline & X Coordinate & Y Coordinate \\
\hline 1 & $-(\mathrm{R} 1 * \sin (\mathrm{pi} *(45-$ alpha1 $) / 180))$ & $(\mathrm{R} 1 * \cos (\mathrm{pi} *(45-$ alpha1 $) / 180))$ \\
\hline 2 & $-((\mathrm{R} 1+\mathrm{a} 1) * \sin (\mathrm{pi} *(45-\mathrm{alpha} 1) / 180))$ & $\left((\mathrm{R} 1+\mathrm{a} 1) * \cos \left(\mathrm{pi}^{*}(45-\mathrm{alpha} 1) / 180\right)\right)$ \\
\hline 3 & $-(\mathrm{R} 2 * \sin (\mathrm{pi} *(45-$ alpha2 $) / 180))$ & $(\mathrm{R} 2 * \cos (\mathrm{pi} *(45-$ alpha2 $) / 180))$ \\
\hline 4 & $-((\mathrm{R} 2+\mathrm{a} 2) * \sin (\mathrm{pi} *(45-\mathrm{alpha} 2) / 180))$ & $\left((\mathrm{R} 2+\mathrm{a} 2) * \cos \left(\mathrm{pi}^{*}(45-\mathrm{alpha} 2) / 180\right)\right)$ \\
\hline 5 & $-(\mathrm{R} 3 * \sin (\mathrm{pi} *(45-$ alpha3 $) / 180))$ & $(\mathrm{R} 3 * \cos (\mathrm{pi} *(45-\mathrm{alpha} 3) / 180))$ \\
\hline 6 & $-((\mathrm{R} 3+\mathrm{a} 3) * \sin (\mathrm{pi} *(45-\mathrm{alpha} 3) / 180))$ & $\left((\mathrm{R} 3+\mathrm{a} 3) * \cos \left(\mathrm{pi}^{*}(45-\mathrm{alpha} 3) / 180\right)\right)$ \\
\hline 7 & $-(\mathrm{R} 4 * \sin (\mathrm{pi} *(45-$-alpha4 $) / 180))$ & $(\mathrm{R} 4 * \cos (\mathrm{pi} *(45-\mathrm{alpha} 4) / 180))$ \\
\hline 8 & $-((\mathrm{R} 4+\mathrm{a} 4) * \sin (\mathrm{pi} *(45-\mathrm{alpha} 4) / 180))$ & $\left((\mathrm{R} 4+\mathrm{a} 4) * \cos \left(\mathrm{pi}^{*}(45-\mathrm{alpha} 4) / 180\right)\right)$ \\
\hline 9 & $-\left(\mathrm{R} 5 * \sin \left(\mathrm{pi}^{*}(45-\right.\right.$ alpha5 $\left.\left.) / 180\right)\right)$ & $\left(\mathrm{R} 5 * \cos \left(\mathrm{pi}^{*}(45-\right.\right.$ alpha5 $\left.\left.) / 180\right)\right)$ \\
\hline 10 & $-\left((\mathrm{R} 5+\mathrm{a} 5) * \sin \left(\mathrm{pi}^{*}(45-\mathrm{alpha5}) / 180\right)\right)$ & $((\mathrm{R} 5+\mathrm{a} 5) * \cos (\mathrm{pi} *(45-$ alpha5 $) / 180))$ \\
\hline 11 & $-\left(\mathrm{R} 6 * \sin \left(\mathrm{pi}^{*}(45-\right.\right.$ alpha6)/180) $)$ & $(\mathrm{R} 6 * \cos (\mathrm{pi} *(45-$ alpha6)/180) $)$ \\
\hline 12 & $-\left((\mathrm{R} 6+\mathrm{a} 6) * \sin \left(\mathrm{pi}^{*}(45-\mathrm{alpha} 6) / 180\right)\right)$ & $\left((\mathrm{R} 6+\mathrm{a} 6) * \cos \left(\mathrm{pi}^{*}(45-\mathrm{alpha} 6) / 180\right)\right)$ \\
\hline 13 & $-(\mathrm{R} 7 * \sin (\mathrm{pi} *(45-$ alpha7 $) / 180))$ & $\left(\mathrm{R} 7 * \cos \left(\mathrm{pi}^{*}(45-\mathrm{alpha} 7) / 180\right)\right)$ \\
\hline 14 & $-\left((\mathrm{R} 7+\mathrm{a} 7)^{*} \sin (\mathrm{pi} *(45-\mathrm{alpha} 7) / 180)\right)$ & $\left((\mathrm{R} 7+\mathrm{a} 7) * \cos \left(\mathrm{pi}^{*}(45-\right.\right.$ alpha7)/180) $)$ \\
\hline 15 & $-(\mathrm{R} 8 * \sin (\mathrm{pi} *(45-$ alpha8 $) / 180))$ & $(\mathrm{R} 8 * \cos (\mathrm{pi} *(45-\mathrm{alpha} 8) / 180))$ \\
\hline 16 & $-\left((\mathrm{R} 8+\mathrm{a} 8) * \sin \left(\mathrm{pi}^{*}(45-\mathrm{alpha} 8) / 180\right)\right)$ & $\left((\mathrm{R} 8+\mathrm{a} 8) * \cos \left(\mathrm{pi}^{*}(45-\right.\right.$ alpha8 $\left.\left.) / 180\right)\right)$ \\
\hline 17 & $-\left(\mathrm{R} 9 * \sin \left(\mathrm{pi}^{*}(45-\right.\right.$-alpha9 $\left.\left.) / 180\right)\right)$ & $(\mathrm{R} 9 * \cos ($ pi*$*(45-$ alpha9 $) / 180))$ \\
\hline 18 & $-((\mathrm{R} 9+\mathrm{a} 9) * \sin (\mathrm{pi} *(45$-alpha9)/180) $)$ & $((\mathrm{R} 9+\mathrm{a} 9) * \cos ($ pi*(45-alpha9)/180)) \\
\hline 19 & $-\left(\mathrm{R} 10 * \sin \left(\mathrm{pi}^{*}(45-\right.\right.$ alpha10)/180) $)$ & $(\mathrm{R} 10 * \cos (\mathrm{pi} *(45-\mathrm{alph} 10) / 180))$ \\
\hline 20 & $-\left((\mathrm{R} 10+\mathrm{a} 10) * \sin \left(\mathrm{pi}^{*}(45-\mathrm{alpha} 10) / 180\right)\right)$ & $\left((\mathrm{R} 10+\mathrm{a} 10) * \cos \left(\mathrm{pi}^{*}(45-\mathrm{alpha} 10) / 180\right)\right)$ \\
\hline 21 & 0 & R11 \\
\hline 22 & 0 & $(\mathrm{R} 11+\mathrm{a} 11)$ \\
\hline
\end{tabular}

\section{Nomenclature}

$\begin{array}{ll}p_{\text {ext }} & \text { External joint load } \\ P & \text { Load increment used for incremental stage } \\ p_{\text {int }} & \text { Internal force } \\ R & \text { Residual force } \\ \delta 1 & \text { Displacement increment computed in the end of iteration process (beginning point } \\ & \text { of incremental stage or first end of arc-length) } \\ \delta 2 & \text { Displacement increment computed by external load (in incremental stage) } \\ \delta 3 & \text { Sub-displacement computed in incremental stage but updated in iterative stage } \\ \delta 4 & \text { Sub-displacement computed using residual force } r \text { (in iterative stage) } \\ \delta 5 & \text { Sub-displacement increment for iterative stage } \\ \beta & \text { Scaling factor } \\ \beta 1 & \text { Sub-scaling factor used to update } \beta \text { computed in iterative stage } \\ \varepsilon & \text { Desired convergence degree } \\ \text { inc_max } & \text { Maximum number of increments } \\ i t \_m a x & \text { Maximum number of iterations } \\ K & \text { System stiffness matrix }\end{array}$




$\begin{array}{ll}\operatorname{det}[K] & \text { Determinant of stiffness matrix } \\ L & \text { Limit Load } \\ W & \text { Weight of truss structure } \\ \delta & \text { Deflection } \\ x, y, z & \text { Coordinates of nodes } \\ P & \text { Material density } \\ N d a & \text { Number of different cross-sectional areas } \\ N n & \text { Number of nodes } \\ N t m & \text { Number of truss member }\end{array}$

\section{References}

Cantu-Paz E 1999 Migration policies and takeover times in parallel Genetic Algorithms. Int. Conf. on Genetic and Evolutionary Computation 775-779

Cardoso J B and Arora J S 1988 Variational method for design sensitivity analysis in nonlinear structural mechanics. AIAA J. 26: 5-22

Choi K K and Santos J L T 1987 Design sensitivity analysis of nonlinear structural systems, Part I: theory. Int. J. Numer. Meth. Eng. 24: 2039-2055

Crisfield M A 1997 Nonlinear finite element analysis of solids and structures, Vol. 2 Advanced topics. UK: John Wiley \& Sons

Eby D, Averill R, Goodman E and Punch W 1999 The optimization of flywheels using an injection island genetic algorithm. Evol. Design Computers 167-190

Gien H 2007 Geometrically nonlinear static analysis of 3D trusses using the arc-length method. 13th Int. Conf. on Comp. Methods and Experimental Meas. Prague, Czech Republic

Goldberg D E and Richardson J 1987 Genetic algorithms with sharing for multimodal function optimization. Genetic algorithms and their applications, 2nd Int. Conf. on Genetic Algor. and Their Appl. Massachusetts, USA, 41-49

Hasancebi O and Erbatur F 2002 Layout optimization of trusses using simulated annealing. Advance Eng. Soft. 33: 681-696

Kamat M P, Khot N S and Venkayya V B 1984 Optimization of shallow trusses against limit point instability. AIAA J. 22: 403-408

Khot N S and Kamat M P 1985 Minimum weight design of truss structures with geometric nonlinear behavior. AIAA J. 23: 139-144

Khot N S, Venkayya V B and Berke L 1976 Optimum structural design with stability constraints. Int. J. Num. Meth. Eng. 10: 1097-1114

Kouhia R and Mikkola M 1999 Some aspects of efficient path-following. Comput. and Struct. 72: 509-524

Krenk S 1995 An orthogonal residual procedure for nonlinear finite element equations. Int. J. Numer. Meth. Eng. 38(5): 823-839

Lamberti L and Pappalettere C 2004 Improved sequential linear programming formulation for structural weight minimization. Comput. Methods Appl. Mech. Eng. 193: 3493-3521

Levy R 1994a Optimization for buckling with exact geometries. Comput. and Struct. 53: 1139-1144

Levy R 1994b Optimal design of trusses for overall stability. Comput. and Struct. 53(5): 1133-1138

Levy R and Perng H S 1988 Optimization for nonlinear stability. Comput. and Struct. 30: 529-535

Levy R, Su M and Kocvara M 2004 On the modeling and solving of the truss design problem with global stability constraints. Struc. Multidisc. Opt. 26: 367-378

Lin C C and Liu I W 1989 Optimal design based on optimality criterion for frame structures including buckling constraints. Comput. and Struct. 31(4): 535-544

Magnusson A 2006 Treatment of bifurcation points with asymptotic expansion. Comput. and Struct. 77: 475-484 
Malott B, Averill R C, Goodman E D, Ding Y and Punch W F 1996 Use of genetic algorithms for optimal design of laminated composite sandwich panels with bending-twisting coupling. 37th Int. Conf. of Struc. Dyn and Mat. AIAA/ASME/ASCE/AHC/ASC. Utah, USA

Memon B A and Su X 2004 Arc-length technique for nonlinear finite element analysis. J. Zhejiang Univ. Science 5(5): 618-628

Ohsaki M 2001 Sensitivity analysis and optimization corresponding to a degenerate critical point. Int. J. Solids Struct. 38: 4955-4967

Ohsaki M 2005 Design sensitivity analysis and optimization for nonlinear buckling of finite-dimensional elastic conservative structures. Comp. Meth. Appl. Mech. Eng. 194: 3331-3358

Ohsaki M and Ikeda K 2006 Imperfection sensitivity analysis of hill-top branching with many symmetric bifurcation points. Int. J. Solids Struct. 43(16): 4704-4719

Ortiz T A and Walls R H 2003 Wtest: test for homogeneity of variances. http://www.mathworks.com/ matlabcentral/fileexchange/

Plaut R H, Ruangsilasingha P and Kamat M P 1984 Optimization of an asymmetric two-bar truss against instability. J. Struct. Mech. 12(4): 465-470

Polheim H 1998 Genetic and evolutionary algorithm toolbox for use with MATLAB. Technical Report. Technical University Ilmnau

Rezaiee-Rojand M and Vejdari-Nogreiyan H R 2006 Computation of multiple bifurcation points. Int. J. Computer-aided Eng. Soft. 23(5): 552-565

Ritto-Correa M and Camotim D 2008 On the Arc-length and other quadratic control methods: Established, less known and new implementation procedures. Comput. and Struct. 86: 1353-1368

Santos J L T and Choi K K 1988 Sizing design sensitivity analysis of nonlinear structural systems, Part II. Int. J. Numer. Meth. Eng. 26: 2039-2055

Schlierkamp-Voosen D and Mühlenbein H 1996 Adaptation of population sizes by competing subpopulations. Int. Conf. on Evolutionary Computation IEEE 330-335

Sedaghati R and Tabarrok B 2000 Optimum design of truss structures undergoing large deflections subject to a system stability constraint. Int. J. Numer. Meth. Eng. 48(3): 421-434

Talaslioglu T 2010 Multiobjective design optimization of grillage systems by scatter search methodology. Int. J. Civil Struc. Eng. 1(3): 477-496

Veldhuizen D V and Lamont G B 1998 Multi-objective evolutionary algorithm research: a history and analysis. Technical Report TR-98-03. Ohio, USA: Department of Electrical and Computer Engineering, Air Force Institute of Technology

Wrigger P, Wagner W and Miehe C 1988 Quadratically convergent procedure for the calculation of stability points in finite elements. Comp. Meth. Appl. Mech. 70: 329-347 